\title{
Modulation of Intersectin-1s Lung Expression Induces Obliterative Remodeling and Severe Plexiform Arteriopathy in the Murine Pulmonary Vascular Bed
}

\author{
Monal Patel, ${ }^{* \dagger}$ Dan Predescu, ${ }^{* \dagger}$ Cristina Bardita, ${ }^{\dagger}$ Jiwang Chen, ${ }^{\dagger}$ Niranjan Jeganathan, ${ }^{\dagger}$ Melanie Pritchard, \\ Salvatore DiBartolo, ${ }^{\dagger}$ Roberto Machado, ${ }^{\ddagger}$ and Sanda Predescu ${ }^{\dagger}$
}

From the Department of Pharmacology \& Internal Medicine, * Division of Pulmonary and Critical Care, and the Department of Pharmacology, ${ }^{\dagger}$ Rush University Medical Center, Chicago, Illinois; the Division of Pulmonary, Critical Care, Sleep and Allergy, ${ }^{\ddagger}$ University of Illinois at Chicago, Chicago, Illinois; and the Department of Biochemistry and Molecular Biology, ${ }^{\S}$ School of Biomedical Sciences, Monash University, Clayton, Victoria, Australia

\begin{abstract}
Accepted for publication
November 22, 2016.

Address correspondence to Sanda Predescu, Ph.D., Division of Pulmonary and Critical Care Medicine, Department of Pharmacology and Internal Medicine, Rush University Medical Center, 1735 W Harrison St, Chicago, IL 60612. E-mail: sanda_predescu@rush.edu.
\end{abstract}

\begin{abstract}
Murine models of pulmonary arterial hypertension (PAH) that recapitulate the plexiform and obliterative arteriopathy seen in PAH patients and help in defining the molecular mechanisms involved are missing. Herein, we investigated whether intersectin-1s (ITSN) deficiency and prolonged lung expression of an ITSN fragment with endothelial cell (EC) proliferative potential $\left(\mathrm{EH}_{\text {ITSN }}\right)$, present in the lungs of PAH animal models and human patients, induce formation of plexiform/obliterative lesions and defined the molecular mechanisms involved. ITSN-deficient mice (knockout/heterozygous and knockdown) were subjected to targeted lung delivery of $\mathrm{EH}_{\mathrm{ITSN}}$ via liposomes for 20 days. Immunohistochemistry and histological and morphometric analyses revealed a twofold increase in proliferative ECs and a 1.35 -fold increase in proliferative $\alpha$-smooth muscle actin-positive cells in the lungs of ITSNdeficient mice, transduced with the $\mathrm{EH}_{\mathrm{ITSN}}$ relative to wild-type littermates. Treated mice developed severe medial wall hypertrophy, intima proliferation, and various forms of obliterative and plexiformlike lesions in pulmonary arteries, similar to PAH patients. Hemodynamic measurements indicated modest increases in the right ventricular systolic pressure and right ventricle hypertrophy. Transcriptional and protein assays of lung tissue indicated $\mathrm{p} 38^{\text {MAPK }}$-dependent activation of Elk- 1 transcription factor and increased expression of $c$-Fos gene. This unique murine model of PAH-like plexiform/obliterative arteriopathy induced via a two-hit pathophysiological mechanism without hypoxia provides novel druggable targets to ameliorate and, perhaps, reverse the EC plexiform phenotype in severe human PAH. (Am J Pathol 2017, 187: 528-542; http://dx.doi.org/10.1016/j.ajpath.2016.11.012)
\end{abstract}

Pulmonary arterial hypertension (PAH) is a severe human disease characterized by narrowing of the small pulmonary arteries, leading to a progressive increase in pulmonary vascular resistance, which frequently leads to right-sided heart failure and death. ${ }^{1-3}$ A common histological finding in patients with severe PAH is the presence of plexiform lesions that obliterate the small to mid-sized pulmonary arterioles. $^{4,5}$ The plexiform pulmonary vascular lesions found at branching points in the small pulmonary arterioles are lumen-obliterating, glomeruloid-like vascular structures, predominantly composed of actively dividing and phenotypically abnormal apoptosis-resistant endothelial cells (ECs). ${ }^{6,7}$ The cellular and molecular mechanisms responsible for the development of plexiform lesions are poorly understood.

Recent evidence suggests the involvement of inflammatory mechanisms in the development of $\mathrm{PAH}^{8}{ }^{8}$ Studies have indicated that inflammation associated with human $\mathrm{PAH}$

\footnotetext{
Supported by NIH grants R01 HL089462 (S.P.) and R01 HL0127022 (S.P.)

Disclosures: None declared.
} 
attracts $\mathrm{CD}^{+} \mathrm{T}$ lymphocytes, which release the cytotoxic protease granzyme B. ${ }^{8-10}$ Recently, we reported that granzyme B is closely associated with ECs in the small pulmonary arterioles and plexiform lesions in human PAH specimens; we have also shown that granzyme B cleaves intersectin-1s (ITSN), a prosurvival protein of lung ECs, and generates an $\mathrm{NH}_{2}$-terminal fragment $\left(\mathrm{EH}_{\text {ITSN }}\right)$ with $\mathrm{EC}$ proliferative potential, which is mediated via sustained phosphorylation of $\mathrm{p} 38^{\mathrm{MAPK}}$ and Elk-1 transcription factor. ${ }^{11}$ Moreover, lung tissue of PAH animal models as well as human PAH lung tissue and pulmonary artery ECs isolated from PAH subjects are deficient of ITSN compared to controls and express the $\mathrm{EH}_{\text {ITSN }}$ product. ${ }^{11}$

Given these findings, we hypothesized that the $\mathrm{EH}_{\mathrm{ITSN}}$ may be responsible for angioproliferation in advanced human PAH. Thus, in the present study, we addressed the in vivo effects of $\mathrm{EH}_{\mathrm{ITSN}}$ expression on lung vascular remodeling using two murine models of ITSN-1 deficiency, the ITSN knockdown mouse $\left(\mathrm{KD}^{I T S N}\right)^{12}$ and the ITSN knockout/heterozygous mouse $\left(\mathrm{K}^{I T S N+-}\right),{ }^{13}$ both transduced with a myc-tagged $\mathrm{EH}_{\text {ITSN }}$ plasmid. Herein, we show that this unique murine model, induced via a two-hit pathophysiological mechanism (ITSN deficiency and $\mathrm{EH}_{\text {ITSN }}$ expression) with no hypoxia and no exposure to any chemical or synthetic compound, develops pulmonary obliterative vascular remodeling and severe plexiform arteriopathy, as seen in human PAH patients, via activation of $\mathrm{p} 38 / \mathrm{Elk}-1 / \mathrm{c}-$ Fos signaling.

\section{Materials and Methods}

\section{Animals}

All animal studies were performed in accordance with the guidelines of the Rush University Institutional Animal Care and Use Committee. K0 $0^{I T S N+/-}$ mice, strain 129SV/J genetic background, were kindly provided by Dr. Melanie Pritchard (Monash University, Clayton, VIC, Australia). Breeding colonies were maintained in the university animal facility. Mice were genotyped by tail snipping standard procedure. All mice, 6 to 8 weeks old, 20 to $30 \mathrm{~g}$ weight, were kept under standardized housing and feeding conditions.

Long-term siRNA-induced $\mathrm{KD}^{I T S N}$ mice were generated by repeated delivery (every 72 hours, for 18 days) of a specific ITSN-1 siRNA sequence (Dharmacon ON-TARGETplus siRNA; $100 \mu \mathrm{g}$ siRNA per mouse; Dharmacon, Lafayette, $\mathrm{CO})$ using cationic liposomes, by retro-orbital injection into mouse lungs (CD1 females; Jackson Labs, Bar Harbor, ME), as described by us. ${ }^{12,14}$ Mice were sacrificed at 2, 6, 12, and 18 days; three mice [control wild-type (wt), vehicle and nonspecific (scrambled) siRNA treated, as well as ITSN siRNA treated] were used per experimental condition and per experiment, with experiments repeated at least three times. Equal doses of the scrambled siRNA and ITSN siRNA were used. No changes in pulmonary cell viability, as indicated by caspase-3 cleavage and terminal deoxynucleotidyl transferase-mediated dUTP nick-end labeling assay, were recorded between days 1 and 18 of this experimental approach. No mouse mortality occurred. Pulmonary inflammatory infiltrates or vascular enlargements were not detected in $\mathrm{KD}^{I T S N}$ mouse lungs. In addition, the Dharmacon ONTARGETplus siRNA reagents and the siRNA concentration used allowed us to minimize the off-target effects and provide a highly specific on-target gene knockdown, while reducing not only the off-target gene modulation but also the extent of ITSN knockdown in other organs. ${ }^{12}$

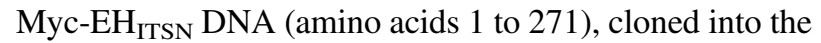
pReceiver/myc-M43 vector, as in the study by Patel et al, ${ }^{11}$ was delivered to mouse lungs similar to siRNA. DNAliposome complexes were prepared at a ratio of 8 nmoles liposomes $/ 1 \mu \mathrm{g}$ myc-EH $\mathrm{ETSN}_{\text {ITS }}$ DNA, a ratio found in pilot studies to induce efficient protein expression without pulmonary toxicity. Long-term myc-EH $\mathrm{ETSN}_{\mathrm{ITS}}$ protein expression was achieved by repeated myc-EH $\mathrm{EHSN}_{\text {ITS }}$ DNA-liposome delivery, every 48 hours, for 18 days. A mutant $\mathrm{EH}_{\text {ITSN- }}$ W263A fragment in which the W263 was substituted with Ala [(A), a substitution that reduces NPF (Asn-Pro-Phe); main target of the EH domains, binding beyond detection ${ }^{15}$ ] was cloned into the same vector and used as control.

At the end of the treatment period, mice were anesthetized by i.p. delivery of $1 \mathrm{~mL} / \mathrm{kg}$ body weight of ketamine hydrochloride/xylazine hydrochloride solution (Sigma-Aldrich, St. Louis, MO). Hemodynamic measurements or tissue harvesting for histology, immunohistochemistry, and morphometric and biochemical analyses were performed. Mice were divided in five groups: group 1, $\mathrm{EH}_{\text {ITSN }}$-transduced $\mathrm{KD}^{I T S N}$; group 2, $\mathrm{EH}_{\text {ITSN }}$-transduced $\mathrm{K}^{I T S N+/-}$; group 3, untreated $\mathrm{KD}^{I T S N}$; group 4, untreated $\mathrm{K} 0^{I T S N+1-}$; and group 5, wt mice. A number of $70 \mathrm{~K} 0^{I T S N+l-}$ mice, strain 129SV/J genetic background, and $110 \mathrm{CD} 1$ mice were used. Age and body weight matched mice were used.

$\mathrm{K} 0^{I T S N+/-}$ mice were genotyped by tail snipping standard procedure. Briefly, mouse tails were chopped and digested in $50 \mu \mathrm{L}$ digestion buffer $(1 \times$ modified gitschier buffer, $0.5 \%$ Triton, and $1 \% 2-\beta$-mercaptoethanol), for 3 minutes at $93^{\circ} \mathrm{C}$, followed by addition of proteinase $\mathrm{K}$ at a final concentration of $1 \mathrm{mg} / \mathrm{mL}$ and incubation at $60^{\circ} \mathrm{C}$ for 2 hours (shaking every 15 minutes). After the 2-hour incubation, proteinase $\mathrm{K}$ was denatured at $95^{\circ} \mathrm{C}$ for 5 minutes. The tubes were then centrifuged at $9,500 \times g$ for 10 minutes, and $1 \mu \mathrm{L}$ of each extracted DNA sample was used for conventional PCR, along with the ITSN primers, as in the study by Patel et al. ${ }^{11}$ The PCR products were resolved onto a $1.2 \%$ agarose gel and visualized using ethidium bromide.

\section{Protein Extraction and Western Blot Analysis}

Mouse lung tissue was homogenized in buffer A $(20 \mathrm{mmol} / \mathrm{L}$ Tris-HCl, pH 7.4, $150 \mathrm{mmol} / \mathrm{L} \mathrm{NaCl}, 1 \mathrm{mmol} / \mathrm{L}$ phenylmethylsulfonyl fluoride, and protease and phosphatase inhibitors), using a Brinkmann Polytron homogenizer (Brinkmann, Oxford, CT). Total lysates were prepared by adding SDS and Triton X-100 to a final concentration of 
$0.3 \%$ and $1 \%$, respectively, for 2 hours, at $4{ }^{\circ} \mathrm{C}$. The resulting lysates were clarified by centrifugation in a Beckman Optima Max-XP ultracentrifuge with a TLA-55 rotor (Beckman, Indianapolis, IN) at $191,500 \times g$ for 45 minutes at $4^{\circ} \mathrm{C}$. Protein concentration was determined using the bicinchoninic acid (Pierce, Rockford, IL) method with a bovine serum albumin standard. Protein samples normalized for total protein were subjected to SDS-PAGE and transferred to nitrocellulose membranes. Strips of nitrocellulose membranes were incubated with the primary and reporter antibodies (Abs) and processed, as in the study by Patel et al. ${ }^{11}$ The reaction was visualized using the enhanced chemiluminescence kit (Pierce) and HyBlot CL films (Denville Scientific Inc., South Plainfield, NJ). Specific Abs were obtained from the following sources: p38 polyclonal $\mathrm{Ab}$, phospho-p38 monoclonal Ab, c-Fos polyclonal Ab, and myc polyclonal Ab from Cell Signaling Technology (Beverly, MA); ITSN-1 monoclonal Ab from BD Biosciences (San Jose, CA); actin monoclonal Ab from Sigma-Aldrich; and Elk1 polyclonal Ab from Santa Cruz Biotechnology (Dallas, TX). The primary Abs were diluted 1:500 (Elk-1), 1:1000 (p38, phospho-p38, myc, ITSN, and c-Fos), and 1:2000 (actin) using 5\% Blotto (Rockland, Limerick, PA) in tris-buffered saline. Horseradish peroxidase-conjugated reporter Abs were from Cappel, Organon Teknika (Durham, NC) and used at 1:1000 dilution; X-ray films will be subjected to densitometry using the ImageJ software version $1.51 \mathrm{~b}$ (NIH, Bethesda, MD; http://imagej.nih.gov/ij).

\section{Elk-1 Transcription Factor Assay}

Nuclear extracts of controls and myc-EH $\mathrm{EH}_{\mathrm{ITSN}}$ transduced mice were prepared using the NE-PER Nuclear and Cytoplasmic Extraction kit (Pierce), as previously described. ${ }^{11}$ The nuclear extracts were then analyzed by enzyme-linked immunosorbent assay (TransAM Kit; Active Motif, Carlsbad, CA), with colorimetric readout quantifiable by spectrophotometry, in a 96-well plate containing the immobilized Elk-1 consensus site oligonucleotide. Activated Elk-1 was detected via an Ab against phosphorylated Elk-1, followed by a horseradish peroxidase-conjugated reporter $\mathrm{Ab}$. The plates were read at $450 \mathrm{~nm}$ using a Dynex plate reader (Chantilly, VA). Data from triplicate wells in three different experiments were expressed as means \pm SEM.

\section{Lung Histology}

Mouse lungs were inflated with $1 \%$ low-melting point agarose in $10 \%$ formalin at a constant pressure of $25 \mathrm{~cm} \mathrm{H}_{2} \mathrm{O}$, allowing for homogeneous expansion of lung parenchyma, and then fixed in $4 \%$ paraformaldehyde for 48 hours and paraffin embedded. ${ }^{12}$ Thin sections ( 4 to $5 \mu \mathrm{m}$ thick), cut longitudinally, were stained with hematoxylin/eosin. Images were acquired with a $\times 20$ lens using a Zeiss AxioImagerM1 microscope (Zeiss, Thornwood, NY) equipped with a color digital camera.

\section{BrdU Proliferation Assay and Immunohistochemistry}

Bromodeoxyuridine (BrdU) solution (Roche, Indianapolis, IN) was injected i.p., every 24 hours, for 2 consecutive days. Sections of paraffin-embedded mouse lung tissue were subjected to double immunohistochemistry using BrdU $\mathrm{Ab}$ (Santa Cruz Biotechnology), with either CD31 Ab (Abbiotec, San Diego, CA) or $\alpha$-smooth muscle actin ( $\alpha$-SMA) Ab (Abcam, Cambridge, MA), followed by the appropriate Alexa Fluor 488 or Alexa Fluor 594 conjugated reporters (Molecular Probes, Eugene, OR), as in the study by Patel et al. ${ }^{11}$ The Abs were diluted in phosphate-buffered saline containing $1 \%$ bovine serum albumin as follows: 1:100 (BrdU), 1:250 (CD31), and 1:500 ( $\alpha$-SMA). All reporters were used at 1:500 dilution in $1 \%$ bovine serum albumin in phosphate-buffered saline. The Prolong Antifade reagent with DAPI (Molecular Probes, Eugene, OR) was used for mounting. Micrographs were acquired using a Zeiss AxioImagerM1 microscope equipped with a color digital camera.

\section{Hemodynamic Measurements}

For the hemodynamic measurements in mice, we used the Millar system, which includes a microtip catheter transducer (model PVR-1030), a pressure volume system, and Power Lab Data acquisition system using Lab Chart Pro software version 7.0 (AD Instruments Inc., Colorado Spring, CO). The catheter was inserted into the right ventricle (RV) via the external right jugular vein. The Fulton index (the ratio of $\mathrm{RV}$ weight to left ventricle + septum weight) or RV weight relative to the animal's body weight was determined as a measurement for RV hypertrophy.

\section{Morphometric Analysis}

Quantification of $\mathrm{BrdU}^{+}$nuclei was performed on smalland medium-sized $(20 \mu \mathrm{m} \geq$ diameter $\leq 100 \mu \mathrm{m})$ blood vessels, as in the study by Bardita et al. ${ }^{12}$ For counting the number of $\mathrm{BrdU}^{+}$cells, a minimum of 25 vessels per section were used (three sections per mouse, three to five mice per experimental condition). All experiments were performed at least three times, with reproducible results.

For assessment of the extent of pulmonary vascular remodeling, we performed a stereological assessment of the (intima + media) thickness and mean linear intercept values on 30 slides for every lung. The stereological software Stepanizer version beta 2.28 (http://www.stepanizer.com) ${ }^{16}$ was used, with a 256-point grid (for assessment of pulmonary artery area) and subsampling with a 16-point (course) grid for assessment of alveolar septa, as in the study by Stacher et al. ${ }^{17}$ The thickness of pulmonary arteries was determined on the basis of sum of point hits in pulmonary artery (intima + media) per 50 histological fields. The mean linear intercept was calculated as described in the study by Bardita et al. ${ }^{12}$ The number of profiles of plexiform lesions per slide was determined by the identification of lesion 
profiles, with the characteristics described in human PAH patients ${ }^{2,6}$ and SUGEN 5416 rat model of PAH. ${ }^{18}$ Uncertain plexiform lesions were not considered for final count.

We also quantified the percentage of affected vessels by sorting the pulmonary in three groups: occluded (either slitlike or no lumen), muscularized (irregular or complete layer of muscle), and nonmuscular. Quantification of affected vessels was performed on small- and medium-sized blood vessels (20 $\mu \mathrm{m} \geq$ diameter $\leq 100 \mu \mathrm{m})$, as above, using three sections per mouse, with three mice in the control group and five mice in the experimental group, with the experiments performed at least three times with reproducible results. This number of mice was considered sufficient to detect relevant differences when significance is set at $P<0.05$.

\section{Statistical Analysis}

For comparison of two groups, $t$-tests (two-tailed) were performed; for multiple groups (three or more groups), oneway analysis of variance and post hoc statistical comparisons with the Bonferroni adjustment were conducted. The data are shown as means \pm SEM, if not otherwise specified. A value of $P<0.05$ was considered significant.

\section{Results}

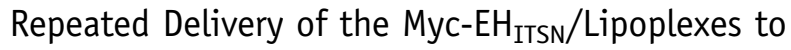
Murine Lungs Leads to Efficient Long-Term Protein Expression

To address the proliferative potential of myc-EH $\mathrm{EH}_{\text {ITSN }}$ in vivo, mice were transduced with the myc-EH $\mathrm{EHSN}_{\mathrm{ITS}}$ / lipoplexes, as described in Materials and Methods. Briefly, myc-EH $\mathrm{EHSN}_{\text {ITS }}$ lipoplexes were delivered repeatedly, every 48 hours, by retro-orbital injection to wt mice, to long-term siRNA-induced $\mathrm{KD}^{I T S N}$ mice, and to $\mathrm{K}^{I T S N+/-}$ mice. Compelling published work, including our studies, demonstrates the efficient and highly specific uptake of the i.v. delivered DNA via cationic liposomes by lung endothelium, mainly proliferative ECs, with no cytotoxicity, as lung endothelium is the first vascular bed encountered by the DNA-lipoplexes delivered retro-orbitally; the positive charge of the cationic liposomes mediates their interaction/ fusion with the negatively charged cell membrane, followed by endocytic internalization. ${ }^{19-22}$ Also, the liposomes/DNA ratio and liposomes' formulation are critical for endosomal escape, nuclear transport, and transfection efficiency. ${ }^{23-25}$ The ratio of $1 \mu \mathrm{g} \mathrm{EH}_{\text {ITSN }}$ DNA/8 nmoles liposomes and the liposomes containing the commonly used lipid imethyldioctadecyl ammonium bromide as cationic head and cholesterol, as hydrophobic group, proved critical for efficient $\mathrm{EH}_{\mathrm{ITSN}}$ expression. Our previous studies indicated that this treatment induces efficient and highly specific ITSN-1 knockdown with $<40 \%$ down-regulation of ITSN in three other murine organs surveyed (ie, heart, liver, and kidney). ${ }^{12}$

Although $\mathrm{K}^{I T S N+/-}$ mice require less intervention for experimental manipulation of ITSN expression, the turning down ITSN gene by a certain amount using the siRNA approach more closely resembles the PAH state, allowing us to observe in real-time the changes in the ECs and other cells' phenotype, and to fashion a useful and refined model of the disease. Western blot (WB) analyses of long-term $\mathrm{KD}^{I T S N}$ mouse lung lysates using ITSN Ab followed by densitometry, indicated the efficient ITSN knockdown for
A
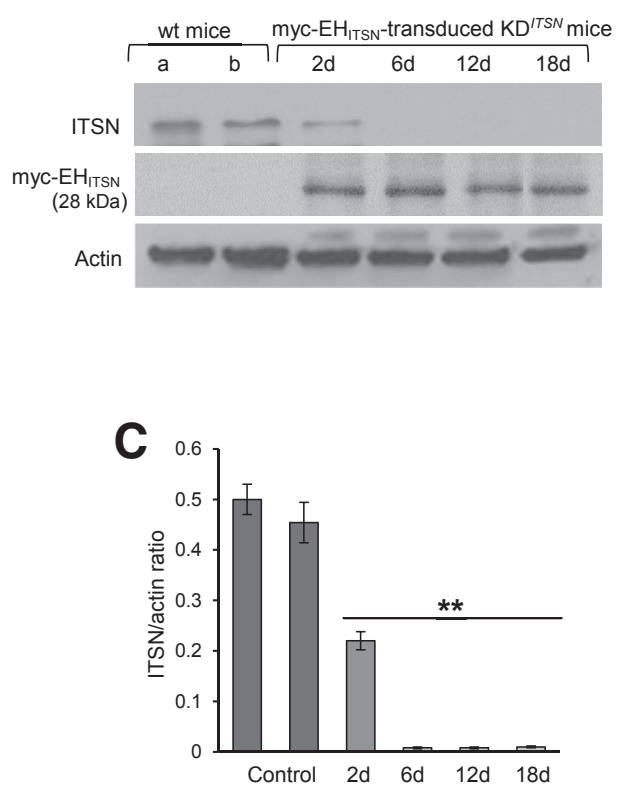

B
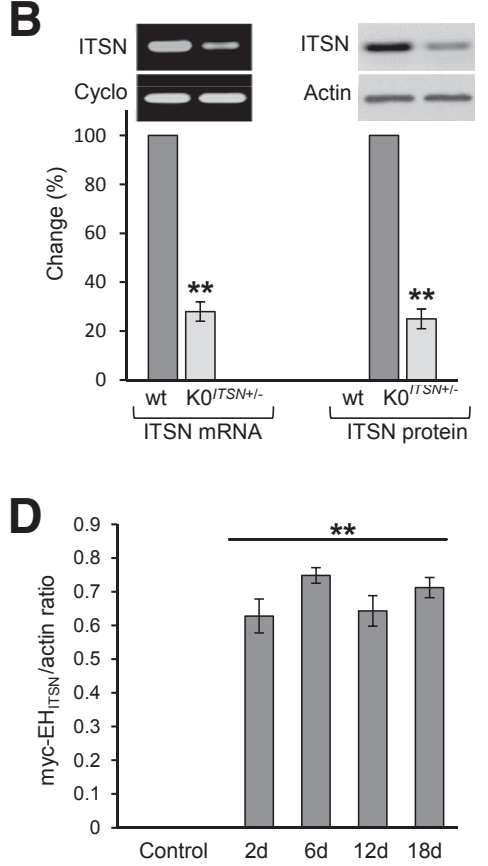

Figure 1 Repeated delivery of lipoplexes containing the ITSN-1-specific siRNA and myc- EH $_{\text {ITSN }}$ plasmid to murine lungs produces efficient longterm ITSN down-regulation and $\mathrm{EH}_{\text {ITSN }}$ protein expression; genotyping of $\mathrm{K} 0^{I T S N}$ mice. A: Lung lysates ( $70 \mu \mathrm{g}$ per lane) of $K D^{I T S N}$ transduced with the myc-EH ITSN lipoplexes (days 2, 6, 12, and 18 of treatment) were subjected to Western blotting (WB) using ITSN antibody (Ab) and myc Ab. Actin was used as loading control. Wild-type (wt) mice (lane a), mice injected with empty liposomes (lane b, top panel) or empty vector (lane b, bottom panel) were used as controls. B: Conventional RT-PCR on lung samples from wt and $\mathrm{KO}^{I T S N+/-}$ mice was used to analyze ITSN-1s mRNA levels, relative to internal control, cyclophilin (cyclo, left panels). ITSN protein levels were analyzed in lung lysates $(70 \mu \mathrm{g}$ total protein per lane) of wt and $\mathrm{KO}^{I I S N+/-}$ mice by WB using ITSN Ab. Actin was used as loading control (right panels). All mice used in this study were genotyped. C and D: Densitometric analyses of

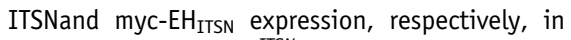
control mice and $K D^{I T S N}$ mice transduced with

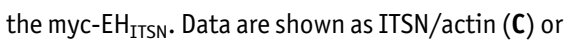
myc-EH ITSN $_{\text {actin (D) ratio. Data are expressed as }}$ means \pm SEM (B-D). $n=3(\mathbf{A}, \mathbf{C}$, and $\mathbf{D}$, mice per group); $n=3$ (A, B-D, different experiments). ${ }^{* \star} P<0.01$ versus wt mice. 
18 days (Figure 1, A and C); likewise, lysates prepared from

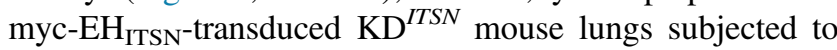
WB analyses using myc Abs followed by densitometry, demonstrate continuous and efficient expression of the myc$\mathrm{EH}_{\text {ITSN }}$ protein for 18 consecutive days (Figure 1, A and D). Wt mice and mice treated with either empty liposomes (Figure 1A) or empty vector (Figure 1A), respectively, were used for comparison. Actin served as loading control (Figure $1 \mathrm{~A}$ ). $\mathrm{K} 0^{I T S N+/-}$ mice were selected by genotyping; conventional RT-PCR applied on $\mathrm{K}^{I T S N+/-}$ mouse lung samples, followed by densitometry, showed a threefold lower ITSN mRNA level by reference to wt mice (Figure 1B). Cyclophilin was used as an internal control. Also, ITSN protein expression was 3.2-fold lower in the $\mathrm{K} 0^{I T S N+1-}$ mice compared to wt mice, as documented by WB analyses of lung lysates, followed by densitometry (Figure 1B).

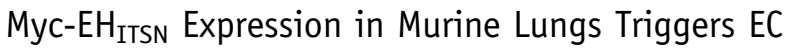 Proliferation and Formation of Vascular Lesions}

To address the proliferative potential of $\mathrm{EH}_{\mathrm{ITSN}}$ in vivo, ITSN-deficient mice $\left(\mathrm{K}^{I T S N+1-}\right.$ and $\left.\mathrm{KD}^{I T S N}\right)$, transduced with the myc-EH $\mathrm{H}_{\mathrm{ITSN}}$, were injected i.p. with the BrdU reagent. Two time points were chosen (one at day 4 and 5)

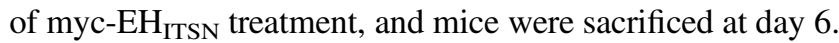
The second one was at day 18 and 19 of myc-EH $\mathrm{EHSN}_{\mathrm{ITSN}}$ treatment, and mice were sacrificed at day 20. Fluorescent imaging of $\mathrm{BrdU}$ incorporation via BrdU/fluorescein isothiocyanate $\mathrm{Ab}$ and morphometry indicated at day 6 , a 1.8 -fold increase in the number of $\mathrm{BrdU}^{+} \mathrm{ECs}$ in myc$\mathrm{EH}_{\text {ITSN}}$-transduced ITSN-deficient mice relative to controls (Figure 2, A and B); CD31 Ab was used for positive identification of ECs. Not only ECs, but also other resident cells of the lung displayed increased BrdU incorporation (Figure 2B). At the same time point, BrdU/ $\alpha$-SMA immunohistochemistry (Figure 2C) and morphometry indicated only a 1.2 -fold increase in proliferation of $\alpha-\mathrm{SMA}^{+}$cells [eg, smooth muscle cells (SMCs) and myofibroblasts]. Only $\alpha-\mathrm{SMA}^{+}$cells in the media were counted. At day 6 , morphometric analyses indicated no significant differences in the number of BrdU-labeled cells (ECs or $\alpha-\mathrm{SMA}^{+}$) between wt- or ITSN-deficient $\left(\mathrm{K}^{I T S N+/-}\right.$ and $\left.\mathrm{KD}^{I T S N}\right)$ mice treated with the myc-EH $\mathrm{EH}_{\text {ITSN }}$ (data not shown). At day 20 , however, fluorescent imaging revealed in the lumen of pulmonary arteries of myc-EH $\mathrm{ETSN}_{\text {ITreated ITSN-deficient }}$ mice numerous BrdU-labelled ECs (Figure 2, D-F) and $\alpha$-SMA ${ }^{+}$(Figure 2, G-I), as well as hypercellularity (Figure 2J). Colocalization of $\alpha$-SMA/BrdU was often detected in either vascular lesions or medial proximity (Figure 2I). Morphometric analyses (Figure 2K) showed $>2.2$-fold increase in $\mathrm{BrdU}^{+} \mathrm{EC}$ nuclei in the myc- $\mathrm{EH}_{\mathrm{ITSN}^{-}}$ transduced ITSN-deficient mice $\left(\mathrm{KD}_{\text {ITSN }}\right.$ and $\left.\mathrm{KO}^{I T S N+/-}\right)$ by comparison to wt mice; there was a 1.35 increase in proliferating $\alpha$-SMA ${ }^{+}$cells in the myc-EH $\mathrm{ITSN}_{\text {-transduced }}$ $\mathrm{K} 0^{I T S N+/-}$ mice versus controls. No significant differences in proliferation of $\mathrm{SMA}^{+}$cells were recorded between $\mathrm{KD}^{I T S N}$ and $\mathrm{K} 0^{I T S N+/-}$ mice (data not shown). Wt mice transduced with the myc-EH $\mathrm{EHSN}_{\mathrm{ITSN}}$ showed a 1.5 -fold increase in $\mathrm{BrdU}^{+}$ECs relative to controls and only a mild increase in $\alpha$-SMA ${ }^{+}$proliferating cells by reference to untreated wt mice.

Mice treated with empty liposomes or empty M43 vector did not show an increase in the number of $\mathrm{BrdU}^{+}$cells by reference to untreated mice, suggesting that the myc- $\mathrm{EH}_{\mathrm{ITSN}}$ has preferential EC proliferative potential, in vivo. Also, wtand ITSN-deficient mice treated with the mutant myc-

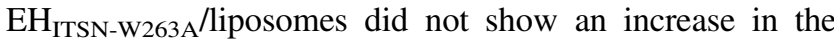
number of $\mathrm{BrdU}^{+}$pulmonary ECs or $\alpha-\mathrm{SMA}^{+}$cells by reference to untreated mice (data not shown).

Frequently, CD31/BrdU Ab immunofluorescence and DAPI nuclear staining of paraffin-embedded mouse lung sections of $\mathrm{EH}_{\text {ITSN }}$-transduced ITSN-deficient mice revealed in the lumen of pulmonary arteries proliferating cells and hypercellularity, suggestive of vascular lesions (Figure 3) (K0 ${ }^{I T S N+/-}$ mice data shown); the inner core cells are either $\mathrm{CD} 1^{+}$or $\mathrm{BrdU}^{+}$or both. The vascular lesions illustrate the severe constriction of the blood vessel lumen (Figure 3A), the onion-skin like structure (Figure 3, B and C) and the $\mathrm{CD} 31^{+} \mathrm{ECs}$, crowded together and pushed into the lumen in a hobnail pattern (Figure 3A). Note the significant colocalization of BrdU/CD31 (Figure 3A), indicative of the proliferative nature of ECs in the lesion. Figure 3B illustrates another lumen-obliterative lesion that comprises two vascular slit-like or irregular channels highly positive for both CD31 and BrdU. DAPI staining reveals the hypercellularity of the vascular lesion. Figure 3C illustrates an obliterative lesion affecting $>50 \%$ of the lumen of the blood vessel. It also appears that the wall of the vessel is partially destroyed. Interestingly, the lesion edge is strongly labeled by $\mathrm{CD} 31 / \mathrm{BrdU}-$ positive ECs, suggesting not only the high EC content, but also their proliferative phenotype. Figure 3D illustrates a complex plexiform-like lesion with several slit-like channels of proliferating ECs and significant hypercellularity (DAPI staining). No significant differences were detected in the extent of pulmonary artery EC proliferation and formation of vascular lesions between $\mathrm{EH}_{\mathrm{ITSN}}$-treated $\mathrm{KD}^{I T S N}$ and $\mathrm{K}^{I T S N+/-}$ mice. Vascular remodeling was not observed in the lung vessels of untreated ITSN-deficient mice.

\section{Histopathological Examination Reveals the Severe Arteriopathy in the Lungs of $\mathrm{EH}_{\mathrm{ITSN}}$-Transduced ITSN-Deficient Mice}

Routine histological examination revealed that pulmonary arteries of the myc-EH $\mathrm{ITSN}$-transduced $\mathrm{K} 0^{I T S N+/-}$ mice had various forms of vascular remodeling (Figure 4). Compared to untreated mice, pulmonary arteries of ITSN-deficient mice transduced with the myc-EH $\mathrm{EH}_{\mathrm{ITSN}}$ were muscularized (Figure 4, A and B) and severely occluded (Figure 4, C-G). Distal extension of smooth muscle and medial thickening of 

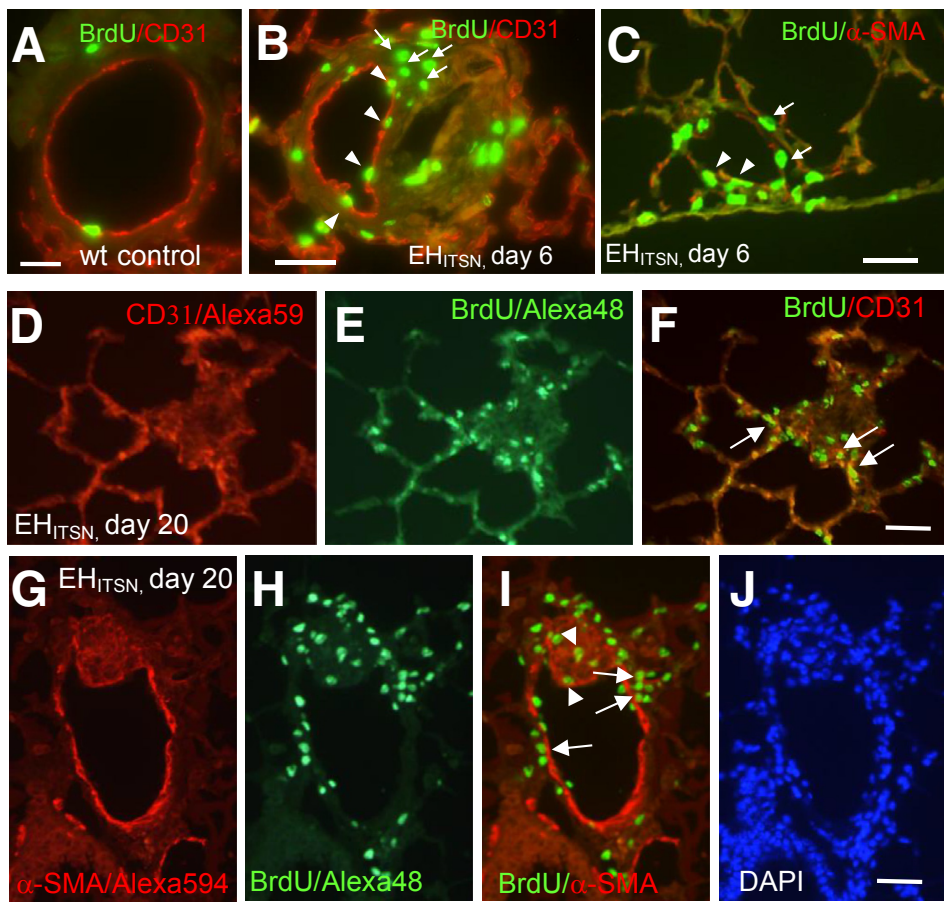

\section{K}

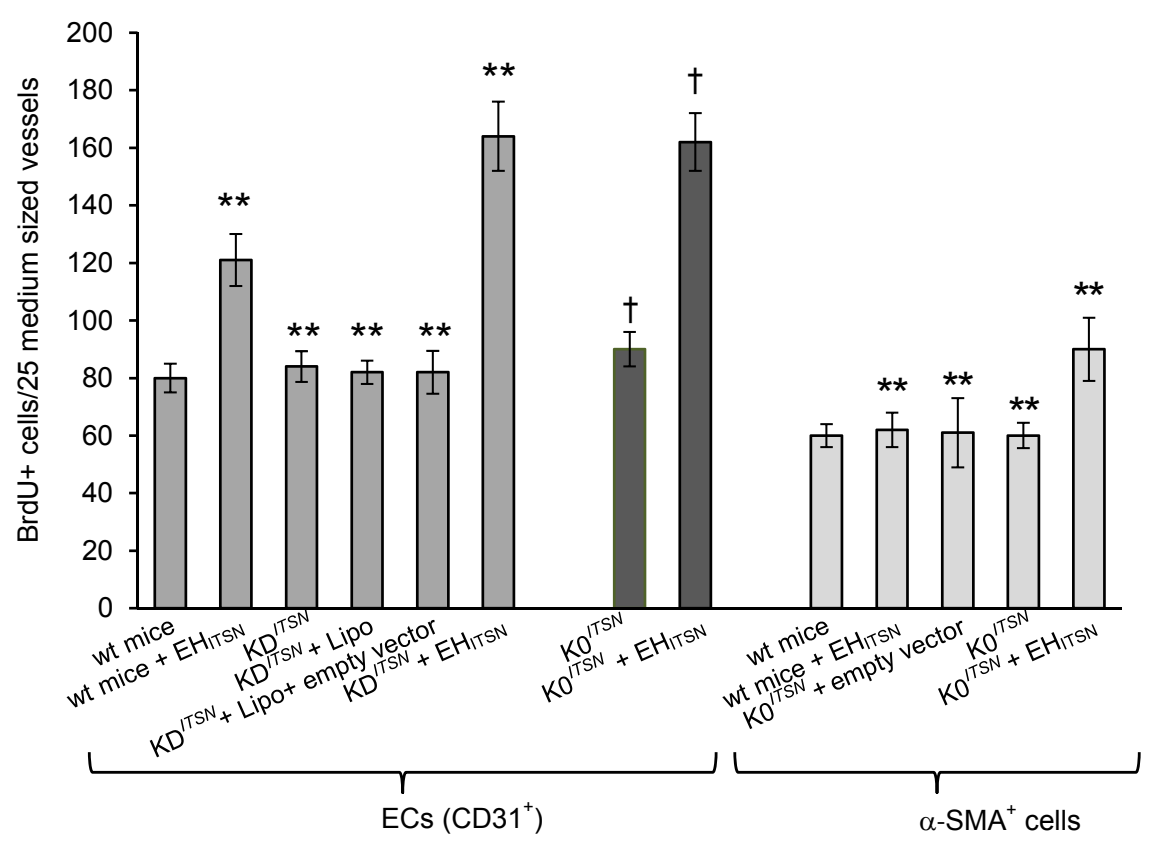

Figure 2 Myc-EH $\mathrm{ITSN}_{\text {N }}$ expression in $\mathrm{KO}^{\mathrm{ITSN}+/-}$ murine lungs triggers proliferation of endothelial cell (EC) and $\alpha$-smooth muscle actin $(\alpha \text {-SMA })^{+}$ lung resident cells. A-C: Wild-type (wt) (A) and

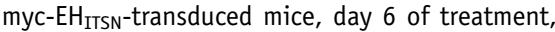
were subjected to bromodeoxyuridine (BrdU) assay, followed by BrdU-fluorescein isothiocyanate and CD31 Alexa Fluor 594 (B) or $\alpha$-SMA Alexa Fluor 594 (C) antibody immunohistochemistry for positive identification of ECs and myofibroblasts, smooth muscle cells, and undifferentiated cells, respectively. Representative micrograph illustrates the BrdU/CD31 colocalization (B, arrowheads) as well as significant proliferation of other lung resident cells (B, arrows). C: $\alpha-\mathrm{SMA}^{+} / \mathrm{BrdU}$ colocalization (arrowheads) within the wall of a pulmonary arteriole or their close proximity (arrows) was also detected. D-I: Representative $\mathrm{CD} 31 / \operatorname{BrdU}(\mathbf{D}-\mathbf{F})$ and $\alpha-\mathrm{SMA}^{+} / \operatorname{BrdU} \quad(\mathbf{G}-\mathbf{I})$ immunohistochemistry of lung sections of myc$\mathrm{EH}_{\mathrm{ITSN}}$-transduced $\mathrm{KO}^{\mathrm{ITSN}+/-}$ mouse lung sections, day 20 of treatment, illustrates clusters of proliferative cells [ECs and $\alpha$-SMA ${ }^{+}$cells ( $F$ and $\mathbf{I}$, arrows, respectively)], as well as other lung resident cells (frequently detected in vascular lesions that obliterate the vessel lumina; I, arrowheads). J: DAPI staining illustrates the hypercellularity associated with the remodeled vessel. K: Quantification of the number of $\mathrm{BrdU}^{+} \mathrm{ECs}$ and $\mathrm{BrdU}^{+} / \alpha-$ $\mathrm{SMAs}^{+}$in the mid-sized lung vessels of controls versus $\mathrm{EH}_{\mathrm{ITSN}}$-treated mice. All data shown are representative of four different experiments with three mice for the control groups and five mice per experimental condition. Wt mice include CD1 as well as $129 \mathrm{SV} / \mathrm{J}$ genetic background mice. No significant differences were noticed in proliferation of $\alpha$-SMAs ${ }^{+}$between wt mice, untreated $\mathrm{KD}^{I T S N}$, and $\mathrm{K}^{I T S N+/-}$ mice. $n=3$ mice per group in three independent experiments $(\mathbf{A}-\mathbf{C}) ; n=12$ (J); $n=4$ different experiments (K); $n=3$ mice for the control groups $(\mathbf{K}) ; n=5$ mice per experimental condition $(\mathbf{K}) .{ }^{*} P<0.01$ versus wt mice; ${ }^{\dagger} P<0.05$ versus $\mathrm{KO}^{I T S N+/-}$ mice. Scale bars: $20 \mu \mathrm{m}(\mathbf{A}-\mathbf{C}) ; 25 \mu \mathrm{m}(\mathbf{D}-\mathbf{F}) ; 40 \mu \mathrm{m}(\mathbf{G}-\mathbf{J})$. a small muscular arteriole (Figure 4A), eccentric cushionlike intima thickening in a pulmonary artery (Figure 4B), concentric onion-skin-like intima thickening with subtotal (Figure 4, C-E) or complete occlusion (Figure 4F) of the lumen were often encountered. A pulmonary artery, approximately $120 \mu \mathrm{m}$ diameter (Figure 4G), displays ECs crowded together and pushed into the lumen in a regular array of bumps (hobnail pattern); this pulmonary artery is associated with a small arteriole affected by both concentric and eccentric intimal proliferation (Figure $4 \mathrm{H}$ ). Another example of severe pulmonary arteriopathy is the stalk-like lesion within the blood vessel lumen (Figure 4, I and J). The lesion in Figure 4I arises from a vessel wall that seems to be affected by eccentric intimal proliferation; the ECs are crowded together and pushed into the lumen in a regular array of bumps (hobnail pattern) (Figure 4I). The lesion in Figure $4 \mathbf{J}$ arises from a muscularized vessel wall, it extends into the vessel lumen, and it shows irregular slit-like channels separated by large hyperchromatic cells. Classic plexiform lesions located alongside bronchioles (Figure $4 \mathrm{~K}$ ) and 

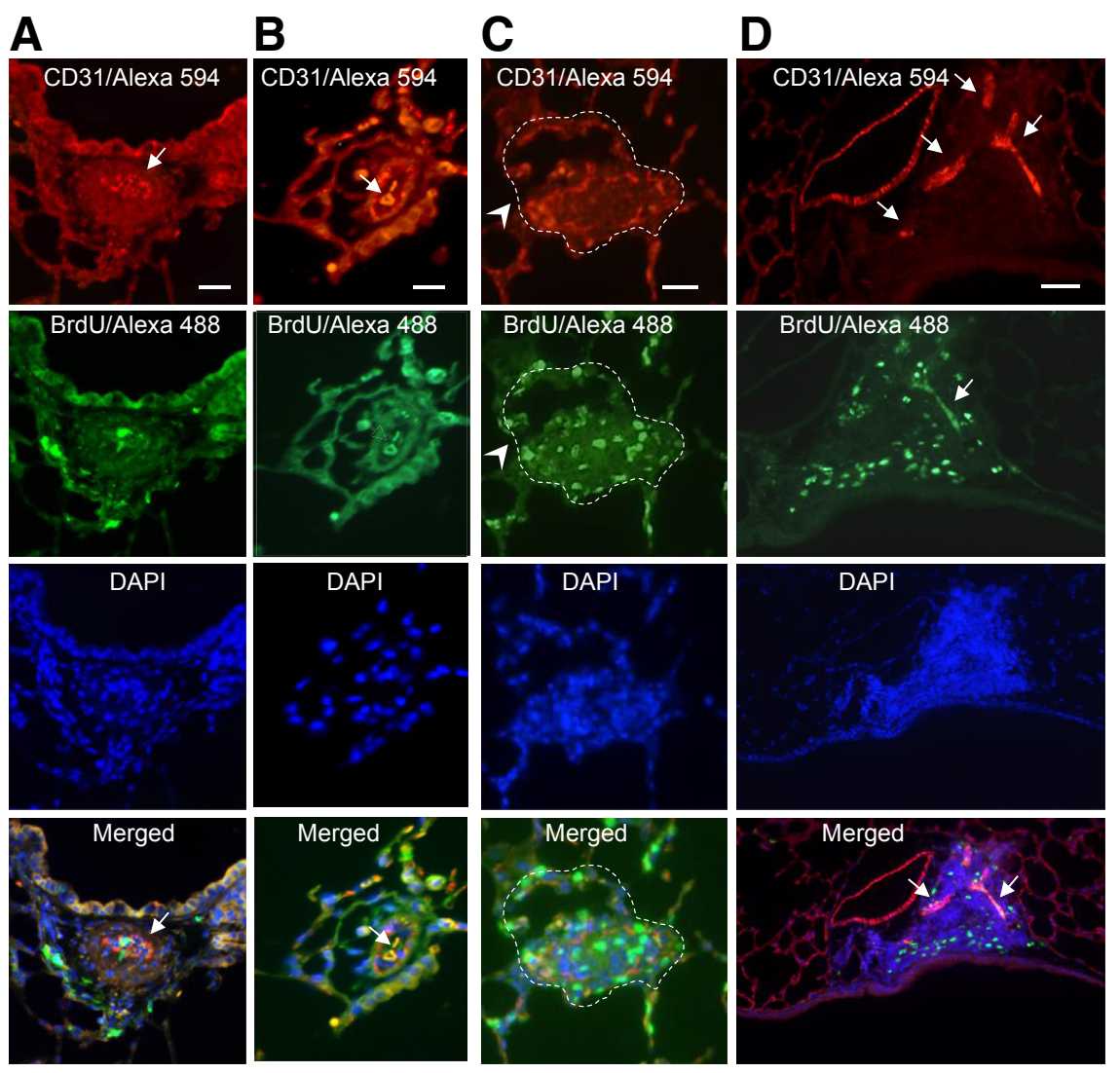

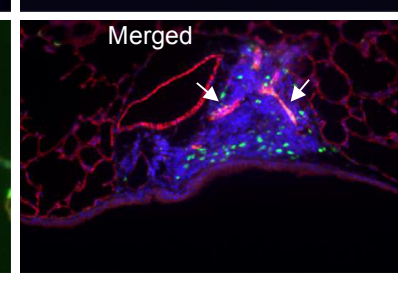

Figure $3 \mathrm{Myc}^{-\mathrm{EH}_{\mathrm{ITSN}}}$ expression in $\mathrm{K}^{I T S N+/-}$ murine lungs triggers severe vasculopathy. Representative double CD31/Alexa Fluor 594 antibody - bromodeoxyuridine (BrdU)/Alexa Fluor 488 immunohistochemistry shows $\mathrm{BrdU}^{+}$endothelial cells (ECS) within complex lesions in myc-EH $\mathrm{EHSN}_{\text {ITS }}$ transduced $\mathrm{KO}^{I T S N+/-}$ mice lungs. $\mathbf{A}$ and D: DAPI staining of the nuclei documents the hypercellularity of intimal cells. The merged images illustrate the significant BrdU/CD31 colocalization within the vascular lesions (A, B, and $\mathbf{D}$, arrows), the severe narrowing of the vessel lumen (arrow, merged image, D) because of concentric medial fibroproliferation, and the presence of slit-like or irregular-shaped $\mathrm{CD} 31^{+}$ channels (arrows, merged images, B and $\mathbf{D}_{\text {, }}$ ); these complex lesions containing proliferative cells, many of them ECs, partially obliterate the lumen of a pulmonary artery with partial destruction of the vessel wall ( $\mathbf{C}$, arrowheads). The dotted lines in $\mathbf{C}$ mark the perimeter of the vessel wall. Data are representative of four different experiments. $n=3$ mice for the control groups and per experimental condition. Scale bars: $50 \mu \mathrm{m}$ (A and D); $25 \mu \mathrm{m}$ (B and C). subpleurally (Figure 4, L and $\mathrm{M}$ ) and projecting into the lung parenchyma (Figure 4, N and O) were often detected. Dilation lesions (thin-walled vein-like vessel framed by elongated $\mathrm{EC}$ nuclei) located distally to the plexiform lesion were also seen (Figure 4, M and O). A favorable section through a complex plexiform lesion (Figure 4, P and Q) that obliterates the lumen of a pulmonary artery illustrates a network of vascular channels lined by rounded ECs. No vascular remodeling was detected in the $\mathrm{K}^{I T S N+/-}$ mice (Figure 4, R and S) or wt mice (data not shown). Inflammatory cells, mainly lymphocytes, with a high nuclear/ cytosol ratio, and occasionally macrophages were present in the pulmonary vascular bed at sites of arteriolar occlusive lesions, either within the lesions or periarteriolar (Supplemental Figure S1).

\section{Morphometric Analyses Revealed Severe Vascular Remodeling in the ITSN-Deficient Murine Lungs Transduced with the Myc-EH ITSN $_{\text {I }}$}

For assessment of the extent of pulmonary vascular remodeling, we performed a stereological assessment of the (intima + media) thickness and mean linear intercept values, as described in Materials and Methods. Separate tissue blocks, 12 to 14 per experimental condition, were stained with hematoxylin and eosin and used for histological analysis of lung tissue and quantification.
For morphometric analysis, images (50) were acquired at $\times 20$ magnification (field area, $341.885 \times 10^{3} \mu^{2}$ ). The

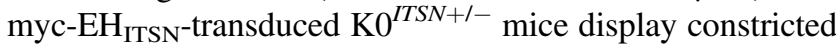
and muscularized pulmonary arteries (Figure 5, A and B). The alveolar septa is thickened (Figure 5C) by comparison to untreated $\mathrm{K} 0^{I T S N+/-}$ mice (Figure 5D). Several vascular profiles (Figure 5, C and D) in $\mathrm{EH}_{\mathrm{ITSN}}$-treated and untreated $\mathrm{K} 0^{I T S N+1-}$ mice are shown. CD31 immunohistochemistry revealed significant enlargement of EC monolayer (Figure 5, F and G) compared to untreated $\mathrm{K}^{I T S N+/-}$ mice (Figure 5E). $\alpha$-SMA staining indicated the medial widening (Figure 5, L and $\mathrm{M}$ ) compared to controls (Figure 5K). DAPI staining revealed the hypercellularity associated with the pulmonary artery wall (Figure 5, I, J, O, and P), compared to controls (Figure 5, $\mathrm{H}$ and $\mathrm{N}$ ).

Intimal occlusion/medial thickening were significantly higher in myc-EH $\mathrm{ITSN}_{\mathrm{IT}}$-transduced $\mathrm{K}^{I T S N+/-}$ mice by comparison to untreated $\mathrm{wt}$ and $\mathrm{K} 0^{I T S N+/-}$ mice (Figure $5 \mathrm{Q}$ ). The mean linear intercept was increased in the $\mathrm{EH}_{\mathrm{ITSN}^{-}}$ transduced $\mathrm{KO}^{I T S N+/-}$ mice compared to controls (Figure 5R). We also performed a morphometric analysis of the number of profiles of vascular lesions. We detected a significant number of vascular lesions in the pulmonary arteries of $\mathrm{EH}_{\text {ITSN }}$-transduced $\mathrm{KO}^{I T S N+/-}$ mice; a small number of lesions were also detected in the wt mice transduced with the $\mathrm{EH}_{\text {ITSN }}$ (Figure 5S). Finally, to determine the percentage of affected vessels, we analyzed the small 


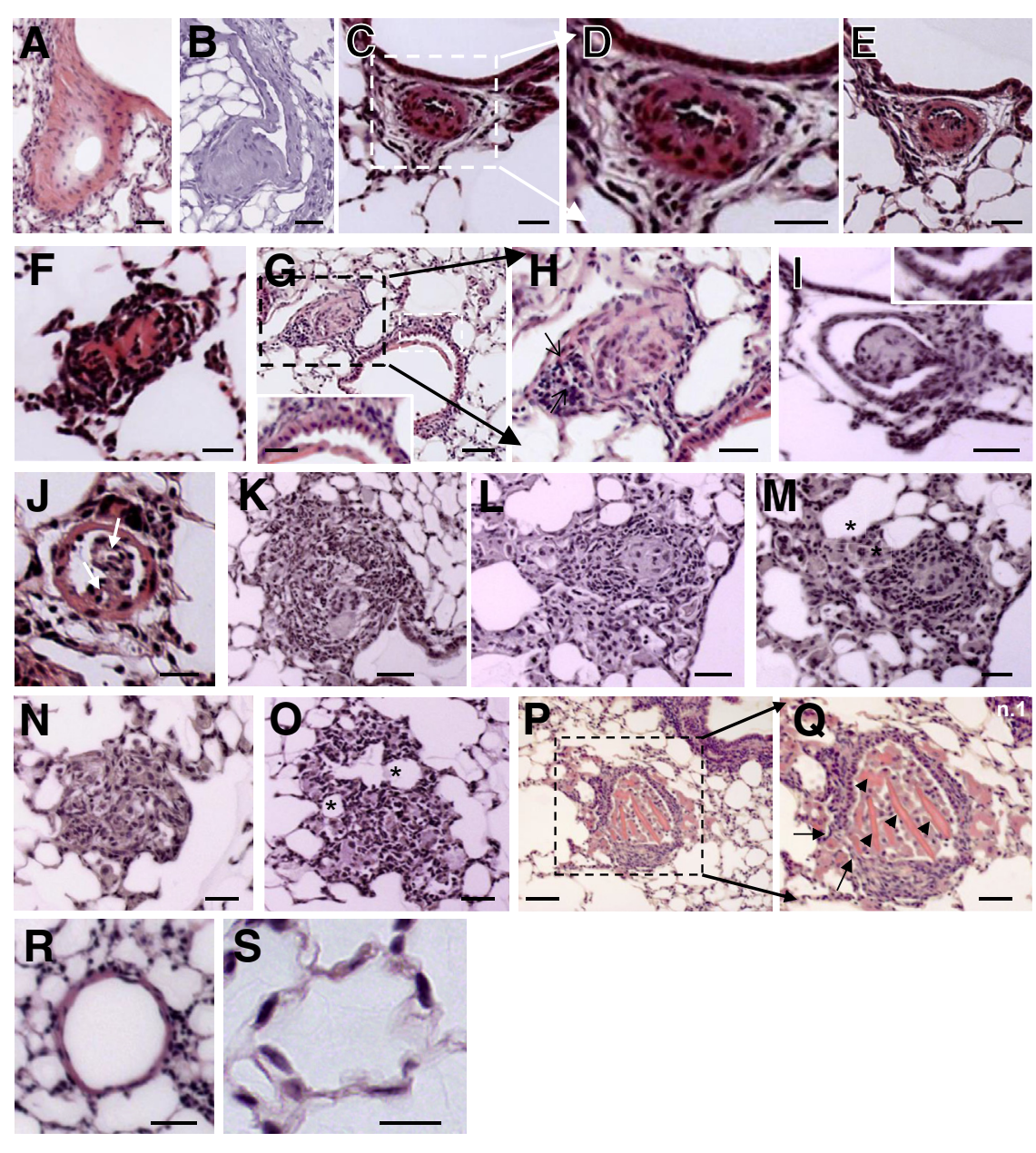

Figure $4 \quad \mathrm{Myc}^{-E_{\mathrm{ITSN}}}$ expression in $\mathrm{KO}^{I T S N+/-}$ mouse lungs leads to vascular remodeling and formation of vascular lesions, including pulmonary vascular occlusion and plexiform-like lesions. Representative hematoxylin and eosin (H\&E) staining of paraffin-embedded lung tissue sections of myc- $\mathrm{EH}_{\mathrm{ITSN}}$-transduced $\mathrm{KO}^{I T S N+/-}$ mice shows various forms of vascular remodeling. $\mathbf{A}$ and $\mathbf{B}$ : Media fibroproliferation with vessel wall thickening. $\mathbf{C}-\mathbf{F}, \mathbf{D}$, and $\mathbf{H}$ : Concentric intimal proliferation with severe obliteration of the vessel lumen (arrows). G: Higher magnification of the lesion in C. The proliferative endothelial cells were located in a hobnail pattern in a vessel, most likely affected by a lesion in other plan ( $\mathbf{G}$, inset). The inset in $\mathbf{G}$ shows the area indicated by a white dashed box in the main image. H: Higher magnification of the black dashed box in G. I and J: Stalk-like lesions. Proliferative endothelial cells arranged in a hobnail pattern (I, inset). $\mathbf{K}-\mathbf{0}$ : Complex plexiform-like lesions. Arrows indicate two irregular slit-like channels separated by large hyperchromatic cells. $\mathbf{M}$ and $\mathbf{0 :}$ Frequently, the plexiform lesions feed into dilated thin-walled vessels (asterisks). $\mathbf{P}$ and $\mathbf{Q}$ : A transversal section through a complex plexiform lesion ( $\mathbf{P}$ and $\mathbf{Q}$ ) illustrates the obliteration of the vessel lumen, partial destruction of the vessel wall ( $\mathbf{Q}$, arrows), and multiple endothelial channels ( $\mathbf{Q}$, arrowheads). Q: Higher magnification of the black dashed box in P. R and S: Untreated $\mathrm{KO}^{I T S N+/-}$ mice lung used as control did not show vascular remodeling. Three independent experiments were performed with three mice for the control groups and five mice for each experimental condition; 8 to 10 H\&E-stained slides per mouse were used. Scale bars: $40 \mu \mathrm{m}(\mathbf{A}, \mathbf{B}, \mathbf{I}, \mathbf{K}, \mathbf{M}$, and $\mathbf{Q}) ; 20 \mu \mathrm{m}(\mathbf{C}, \mathbf{D}, \mathbf{F}$, and $\mathbf{~})$; $35 \mu \mathrm{m}(\mathbf{E}) ; 30 \mu \mathrm{m}(\mathbf{H}, \mathbf{N}, \mathbf{0}$, and $\mathbf{G}$, inset); $60 \mu \mathrm{m}(\mathbf{G}$, main image, and $\mathbf{P}) ; 50 \mu \mathrm{m}(\mathbf{L}$ and $\mathbf{R}) ; 10 \mu \mathrm{m}(\mathbf{S})$.

pulmonary arteries $(20 \mu \mathrm{m} \geq$ diameter $\leq 100 \mu \mathrm{m})$, in regard to their degree of muscularization, no muscularization, or obliteration; the results indicate a modest increase in vessels surrounded by irregular or complete layer of muscle and a significant increase in obliterated vessels (slit-like or full occlusion) in ITSN-deficient mice $\left(\mathrm{KD}^{I T S N}\right.$ or $\mathrm{K}^{I T S N+/-}$ ) compared to the wt mice or mice not treated with the $\mathrm{EH}_{\text {ITSN }}$ (Table 1).

\section{Collagen Deposition Contributes to Vascular Remodeling in $\mathrm{EH}_{\mathrm{ITSN}}$-Transduced $\mathrm{KO}^{\mathrm{ITSN}+/-}$ Mouse Lungs}

To get more insights into the nature of vascular remodeling and alveolar wall thickening in the ITSN-deficient murine lungs transduced with the myc-EH $\mathrm{EHSN}_{\mathrm{ITS}}$, we examined whether collagen deposition contributes to the vascular remodeling process. Masson's trichrome staining of lung sections indicates collagen deposition within vascular obliterative lesions (Figure 6, A-C) and within muscle layers of remodeled pulmonary arteries (Figure 6, D and E). Frequently, collagen accumulation was seen in the interstitium, most likely stimulated by leakiness of the endothelial barrier and interstitial edema (Figure 6F). Both untreated $\mathrm{K} 0{ }^{I T S N+/-}$ mice used as controls and $\mathrm{EH}_{\mathrm{ITSN}^{-}}$ transduced $\mathrm{K}^{I T S N+/-}$ mouse lungs typically showed weak collagen staining of the basement membranes of the alveolar epithelium (Figure 6, G and H). Occasionally, Masson's trichrome staining revealed focal areas of collagen accumulation within the alveolar space of $\mathrm{EH}_{\mathrm{ITSN}}$-transduced $\mathrm{K} 0^{I T S N+/-}$ mouse lungs (Figure $6 \mathrm{H}$ ).

\section{Myc-EH ITSN Transduced $\mathrm{KO}^{\mathrm{ITSN}+/-}$ Mice Showed Modest Increase in RVSP and RV Hypertrophy}

Given the severe lung vasculopathy of the myc- $\mathrm{EH}_{\mathrm{ITSN}^{-}}$ transduced mice, we next performed measurements of right ventricular systolic pressure (RVSP) and RV hypertrophy. $\mathrm{K} 0{ }^{I T S N+/-}$ mice were randomized in three groups: untreated, empty liposomes treated, and exposed to myc-EH $\mathrm{EH}_{\mathrm{ITSN}}$. Despite the severe lung vascular remodeling and significant obliterative and plexiform arteriopathy in the treated mice compared to controls, the RVSP values were not elevated enough to match the extent of vascular 

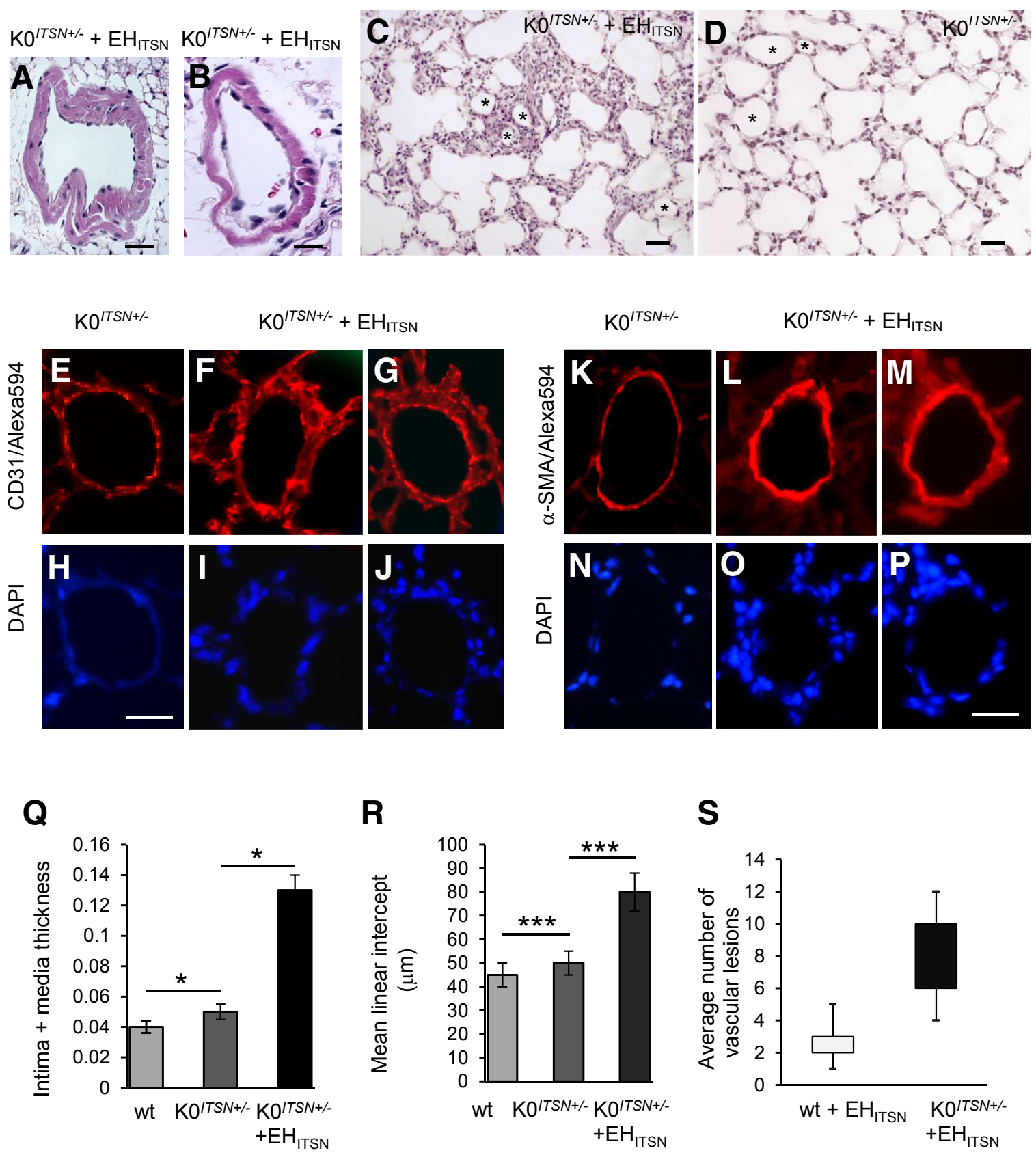

Figure 5 Histological and morphometry analyses revealed the severity of vascular remodeling in the lungs of myc- $\mathrm{EH}_{\text {ITSN }}-$ transduced $^{\text {KITSN }+/-}$ mice. A-C: Representative hematoxylin and eosin staining illustrates medial proliferation (A and $\mathbf{B}$ ) and alveolar septa thickening (C) in myc- $\mathrm{EH}_{\mathrm{ITSN}}$-transduced $\mathrm{KO}^{\mathrm{IISN}+/-}$ mice. D: Lung morphology of untreated $\mathrm{KO}^{I T S N+/-}$ mice. Several vascular profiles in $\mathrm{EH}_{\mathrm{ITSN}}$-treated (C) and untreated $\mathrm{KO} \mathrm{ITN+}^{I T S-}$ (D) mice are marked by asterisks. Representative CD31/DAPI (E-J) and $\alpha$-smooth muscle actin $(\alpha-S M A) / D A P I ~(K-P)$ of lung arterioles in untreated mice versus $K 0^{I T S N+/-}$ mice transduced with the myc-EH ITSN. Q: Intima plus media thickening in $\mathrm{KO}^{I T S N+/-}$ plus myc-EH $\mathrm{ITSN}_{\mathrm{ISN}}$ versus controls (wt and $\mathrm{K} 0^{I T S N+/-}$ mice). A, B, $\mathbf{Q}$, and $\mathbf{R}$ : The

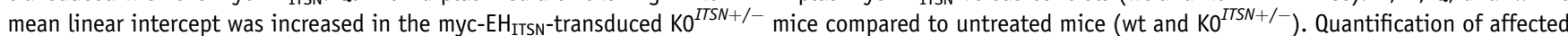
vessels was performed on small- and medium-sized blood vessels $(20 \mathrm{~mm} \geq$ diameter $\leq 100 \mathrm{~mm})$, as above, using three sections per mouse, three mice in the control group and five mice in the experimental group, with the experiments performed at least three times with reproducible results (A, B, Q). S: Average

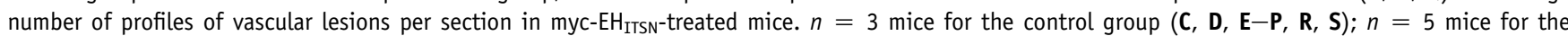
experimental group $(\mathbf{C}, \mathbf{D}, \mathbf{E}-\mathbf{P}, \mathbf{R}, \mathbf{S}) ; n=3$ independent experiments $(\mathbf{C}, \mathbf{D}, \mathbf{E}-\mathbf{P}, \mathbf{R}, \mathbf{S})$. Data are expressed as means $\pm \mathbf{S E M}(\mathbf{Q}-\mathbf{S}) .{ }^{*} P<0.05,{ }^{* * *} P<0.001$. Scale bars: $20 \mu \mathrm{m}(\mathbf{A}, \mathbf{C}$, and $\mathbf{D}) ; 10 \mu \mathrm{m}$ (B); $35 \mu \mathrm{m}$ (E-J); $40 \mu \mathrm{m}(\mathbf{K}-\mathbf{P})$.

remodeling (Figure 7A). The Fulton's index, [RV/(left ventricle + septum)], and the RV weight/body weight ratio, indicative of RV hypertrophy, were minimally higher in

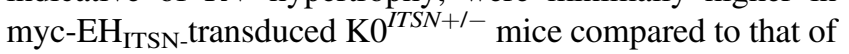

control mice (Figure 7, B and C). Both $\mathrm{K} 0^{I T S N+/-}$ mice, on a $129 \mathrm{SV} / \mathrm{J}$ genetic background that is more resistant to $\mathrm{PAH},{ }^{26}$ and $\mathrm{KD}^{I T S N}$ on a CD1 genetic background (data not shown) were used. Despite their reported resistance to PAH, 
Table 1 Quantification of Pulmonary Arteries Remodeling: Percentage of Vessels Affected

\begin{tabular}{|c|c|c|c|c|}
\hline Mouse model/remodeling & wt & $w t+E_{\text {ITSN }}$ & $\mathrm{KD}^{I T S N}$ or $\mathrm{K}^{I T S N+/-}$ & $\mathrm{KD}^{I T S N}$ or $\mathrm{K}^{I T S N+/-}+\mathrm{EH}_{\text {ITSN }}$ \\
\hline $\begin{array}{l}\text { Obliteration (slit-like or no } \\
\text { lumen) }\end{array}$ & & $8.0 \pm 3.2$ & & $60.0 \pm 8.0$ \\
\hline Nonmuscularized & $94.7 \pm 2.1$ & $80.0 \pm 7.5$ & $94.0 \pm 9.5$ & $10.0 \pm 2.6$ \\
\hline
\end{tabular}

Data are shown as means \pm SEM. If obliteration and muscularization affected the same pulmonary artery, only obliteration was counted. Quantification of affected vessels was performed on small- and medium-sized blood vessels ( $20 \mu \mathrm{m} \geq$ diameter $\leq 100 \mu \mathrm{m})$, as above, using three sections per mouse, three mice in the control group and five mice in the experimental group, with the experiments performed at least three times with reproducible results.

$\mathrm{EH}_{\mathrm{ITSN}}$, intersectin-1s fragment with endothelial cell proliferative potential; K0, knockout/heterozygous; KD, knockdown; wt, wild type.

no differences were noted in the hemodynamic values between the two genetic models.

Myc-EH $\mathrm{HTSN}_{\mathrm{T}}$ Expression Leads to Activation of $\mathrm{p} 38^{\mathrm{MAPK}}$ as well as Downstream Elk-1 Transcription Factor in $\mathrm{KO} \mathrm{ITSN}+/-^{\mathrm{IT}}$ Mouse Lungs

Because our previous studies indicated that myc-EH $\mathrm{EH}_{\text {ITSN }}$ expression in cultured pulmonary artery ECs triggers a novel $\mathrm{p} 38^{\mathrm{MAPK}} / \mathrm{Elk}-1 / \mathrm{c}-$ Fos proliferative signaling pathway and that phospho-p38 level is increased in the lung tissue of animal models of PAH as well as in human PAH lung tissue ${ }^{11}$ we next addressed if myc-EH ${ }_{\text {ITSN }}$ expression in $\mathrm{K} 0^{I T S N+/-}$ mouse lungs activates this $\mathrm{p} 38$-dependent proliferative signaling. Mouse lung lysates were analyzed by WB with specific phospho-p38 Abs. Densitometry indicated that myc-EH $\mathrm{HTSN}_{\mathrm{ITS}}$ expression leads to a 4.4-fold increase in $\mathrm{p} 38^{\mathrm{MAPK}}$ activation in myc-EH $\mathrm{ITSN}^{- \text {transduced }} \mathrm{K}^{I T S N+/-}$ mice lungs compared to control mice (Figure 8A). Nuclear extracts prepared from myc-EH ${ }_{\text {ITSN }}$ expressing $\mathrm{K}^{I T S N+/-}$ mouse lung tissue showed a 5.6-fold higher Elk-1 activation compared to controls (Figure 8B). To investigate c-Fos expression, nuclear extracts were subjected to $\mathrm{WB}$, followed by densitometry. We detected on average, a sixfold increase in c-Fos expression in treated $\mathrm{K} 0^{I T S N+/-}$ mice versus control (Figure 8C). On the basis of these data, we concluded that similar to human PAH lung tissue, myc-EH $\mathrm{EH}_{\mathrm{ITSN}}$ expression in $\mathrm{K} 0^{I T S N+/-}$ mouse lungs leads to activation of $\mathrm{p} 38^{\mathrm{MAPK}}$ as well as downstream Elk-1 transcription factor and increased expression of $c$-Fos gene.

\section{Discussion}

This study demonstrated that mice with targeted disruption of ITSN gene and lung expression of $\mathrm{EH}_{\mathrm{ITSN}}$, the
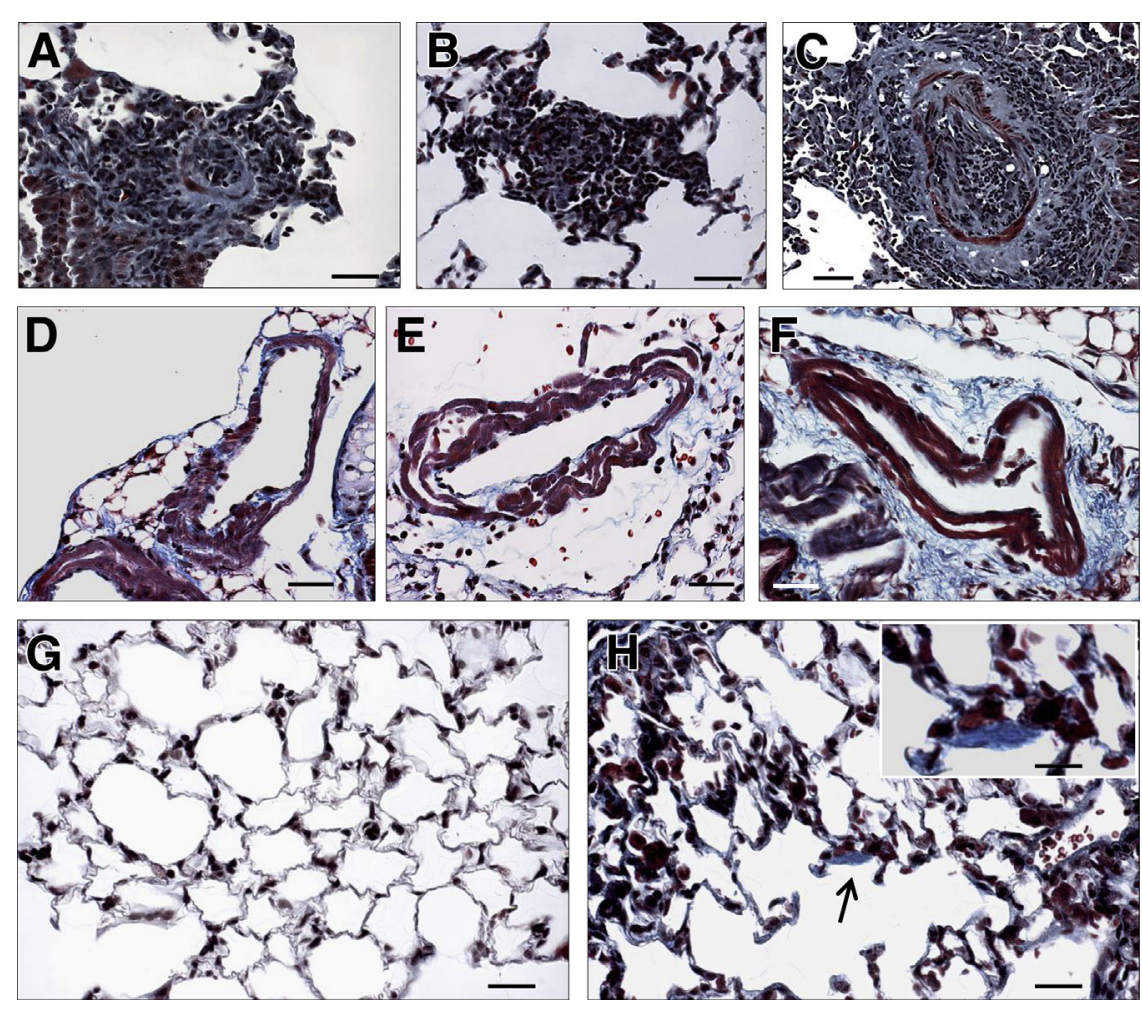

Figure 6 Collagen deposition within plexiform lesion, perivascular spaces, and alveolar septa, in $\mathrm{EH}_{\mathrm{ITSN}}$-transduced $\mathrm{KO}^{\mathrm{ITSN}+/-}$ mouse lungs. Representative Masson's trichrome staining of $\mathrm{EH}_{\mathrm{ITSN}^{-}}$ transduced $\mathrm{KO}^{I T S N+/-}$ mouse lung sections illustrates collagen deposition within vascular obliterative lesions in pulmonary vessels with a diameter between 20 and $60 \mu \mathrm{m}(\mathbf{A}-\mathbf{C})$, within the layers of muscularized vessel walls (D-F), and in the interstitial space (F). Limited collagen deposition was seen in the alveolar septa of both untreated $\mathrm{KO}^{I T S N+/-}$ mice $(\mathbf{G})$ and $\mathrm{EH}_{\mathrm{ITSN}}$-treated $\mathrm{KO}^{I I S N+/-}$ mice $(\mathbf{H})$. Occasionally, however, focal collagen deposition was seen in the alveolar wall of $\mathrm{EH}_{\text {ITSN }^{-}}$ treated $\mathrm{KO}^{I I S N+/-}$ mice (arrow and inset in $\mathbf{H}$ ). $n=3$ mice for the control groups $(\mathbf{G}) ; n=5$ mice for the experimental group (A-F and $\mathbf{H}) ; n=6$ Masson's trichrome stained slides per mouse. Scale bars: $30 \mu \mathrm{m}(\mathbf{A}-\mathbf{H}) ; 15 \mu \mathrm{m}$ (inset). 

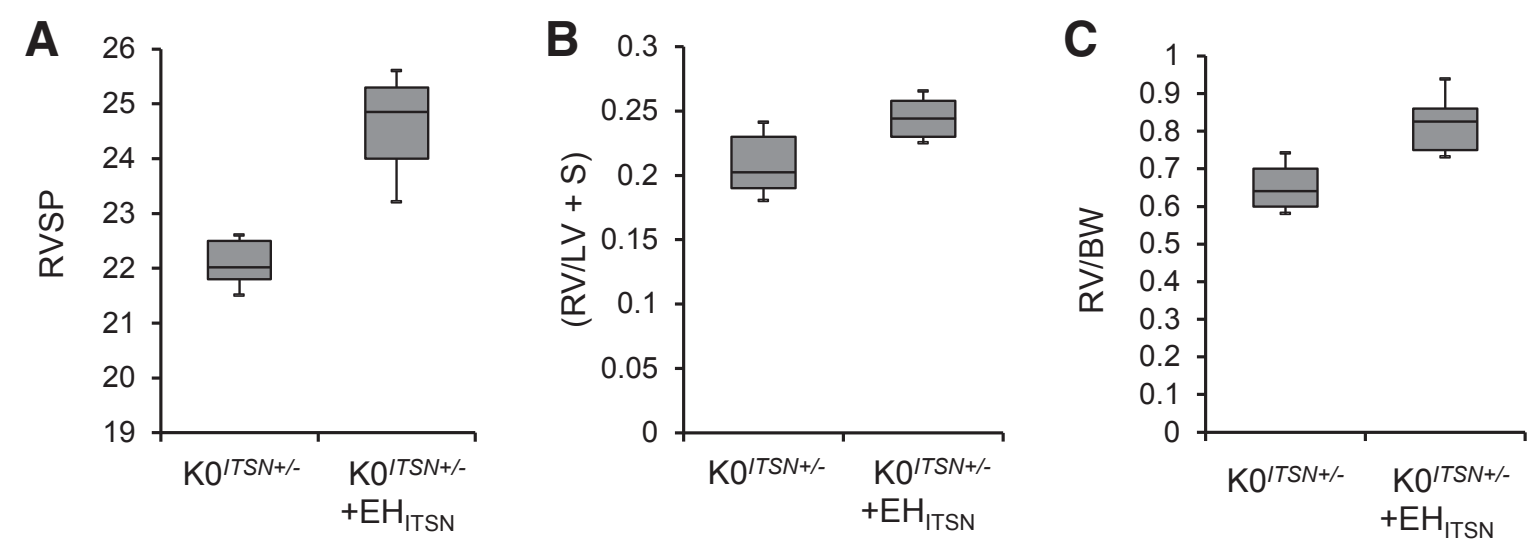

Figure $7 \quad \mathrm{Myc}_{\mathrm{C}} \mathrm{EH}_{\mathrm{ITSN}}$-transduced $\mathrm{KO}^{\mathrm{IISN}+/}$ - mice show modest increase in right ventricular systolic pressure (RVSP) and right ventricle (RV) hypertrophy.

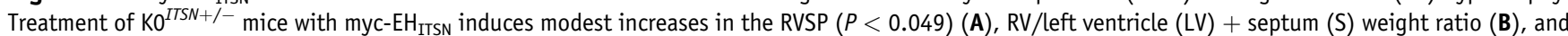
RV weight/body weight $(B W)(P<0.05)(C)$. Lines within the boxes show medians; boxes show 25th and 75th percentiles of the data, respectively. Data are expressed as medians \pm SEM. $n=3$ independent experiments were performed; $n=5$ mice per experimental condition.

$\mathrm{NH}_{2}$-terminal protein fragment of ITSN produced by granzyme B proteolytic cleavage during inflammation associated with PAH, develop PAH-like arterial remodeling, with severe medial wall hypertrophy and intima proliferation in pulmonary arteries as well as obliterative and complex plexiform-like lesions, as seen in PAH patients. No hypoxia and no chemical/synthetic compounds were used. This is relevant because ITSN deficiency and expression of the $\mathrm{EH}_{\text {ITSN }}$ characterize the lung tissue of several experimental animal models of PAH, human PAH lung tissue, as well as pulmonary artery ECs isolated from idiopathic PAH patients. ${ }^{11}$ The pulmonary vascular inflammation associated with PAH attracts the proinflammatory $\mathrm{CD}^{+} \mathrm{T}$ lymphocytes that surround the plexiform lesions and release the cytotoxic protease granzyme B. ${ }^{3,9}$ Granzyme B is present in the milieu of plexiform lesions in human PAH lungs in close proximity of ECs, ${ }^{11}$ suggesting that granzyme B may cleave ITSN and generate the $\mathrm{EH}_{\text {ITSN }}$ with proliferative potential, leading to hyperproliferation of ECs and perhaps of pulmonary artery SMCs. The plexiform lesion is a hallmark of the pulmonary arteriopathy in severe $\mathrm{PAH}$; it has a distinct glomeruloid structure that consists of a network of channels lined by ECs and separated by hyperchromatic and oval core cells. $^{2,4,27-29}$ Consistent with the effects of myc-EH ITSN $_{\text {in }}$ cultured ECs, we detected clusters of proliferating ECs in vivo in myc-EH $\mathrm{ITSN}_{\text {-transduced }} \mathrm{K}^{I T S N+/-}$ mice. It has been suggested that formation of plexiform lesions involving ECs, pulmonary artery SMCs, and possibly cells
A

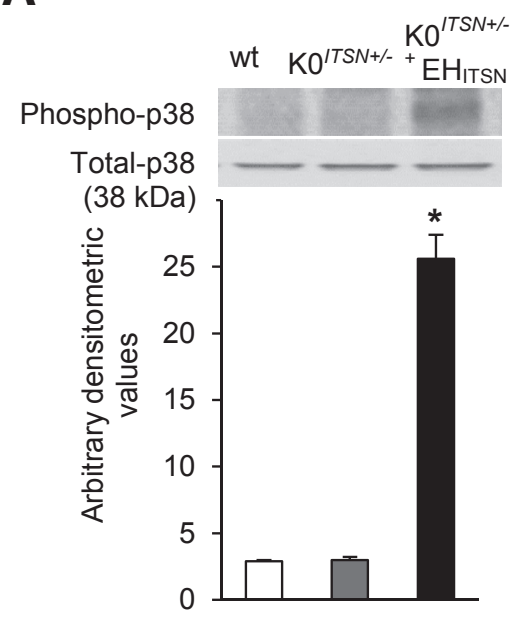

B

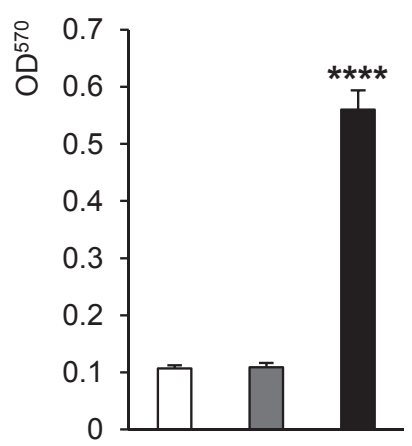

C

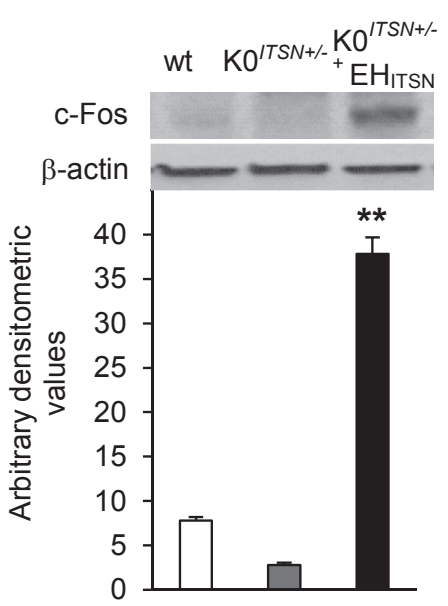

Figure $8 \quad \mathrm{Myc}_{\mathrm{E}} \mathrm{EH}_{\mathrm{ITSN}}$ expression leads to activation of $\mathrm{p} 38^{\mathrm{MAPK}}$ as well as downstream Elk-1 transcription factor and c-fos expression in $\mathrm{KO}^{\mathrm{IISN}+/-}$ mouse

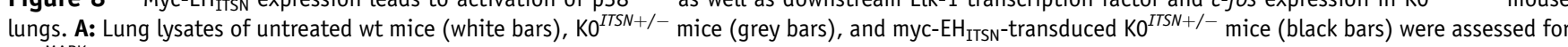
p3 $8^{\text {MAPK }}$ phosphorylation. Total p38 kinase was used as a loading control. Densitometry values are representative for three independent experiments. B: Nuclear extracts prepared from controls and treated mice were assayed for Elk-1 activity. Data are representative of three independent experiments performed

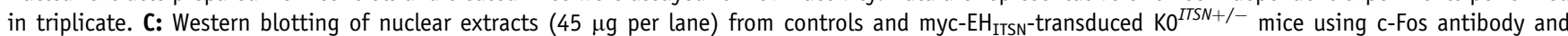
consequent densitometry analysis. Data were normalized to $\beta$-actin. Data represent three different experiments. Data are expressed as means \pm SEM $(\mathbf{A}-\mathbf{C})$. $n$ $=3$ mice per group $(\mathbf{A}-\mathbf{C}) .{ }^{*} P<0.05,{ }^{* *} P<0.01$, and ${ }^{* * * * P}<0.005$ versus wt mice. 
of nonvascular origin is a major factor responsible for the high vascular resistance in severe human $\mathrm{PAH}^{30}$ The lesions observed in ITSN-deficient mice transduced with the

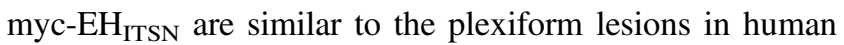
PAH patients. These complex lesions were widespread and developed at different vascular sites, often growing into the lumen and causing severe obliteration. The stalk-like lesions arise from muscularized vessel walls and display oval hyperchromatic cells. We have observed obliterative and complex plexiform-like lesions with slit-like channels of proliferating ECs and significant hypercellularity that fully or partially occluded pulmonary vessels. Whether these endothelium-lined channels are functional blood vessels or just slits is still under debate. Often, these complex lesions with significant hypercellularity and various degrees of concentric and intimal proliferation projected into the lung parenchyma, as observed in advanced human PAH. These lesions also display a rich matrix of collagen; collagen deposition has also been found within muscle layers of remodeled pulmonary arteries, contributing thus to the vascular medial thickening. Aberrant pulmonary artery EC proliferation and lesion formation are important markers of disease progression and, thus, ITSN deficiency and its $\mathrm{EH}_{\text {ITSN }}$ fragment, able to replicate the characteristic obliterative lesions seen in human $\mathrm{PAH}$, seem to be critical factors to the development and progression of pulmonary vascular remodeling. Moreover, proliferation of pulmonary artery SMCs observed in the lung vessels of myc-EH $\mathrm{EH}_{\text {ITSN }}$ expressing mice, strongly suggests that in this mouse model both pulmonary arterial ECs and SMCs are hyperproliferative, they cross talk, and this cross talk may implicate the local immune $\mathrm{T}$ lymphocytes, as well. The possibility that SMCs might have taken up the $\mathrm{EH}_{\text {ITSN }}$ fragment and show proliferative responses similar to ECs cannot be ruled out.

However, despite significant histopathology, these mice did not develop severe RVSP and displayed modest signs of RVH. Baseline RVSP measurements in wt-unchallenged mice can vary from 10 to $20 \mathrm{mmHg}$ up to $22 \mathrm{mmHg}$ and up to $35 \mathrm{mmHg}$ after chronic hypoxia exposure. ${ }^{31}$ Our data show a modest increase in the RVSP values (from 21 to $25.5 \mathrm{mmHg}$ ), only 20 days of $\mathrm{EH}_{\text {ITSN }}$ treatment under normoxic conditions. This relatively short duration of treatment with the myc-EH $\mathrm{EHSN}_{\text {ITS }}$ fragment with no chronic hypoxia and/or chemical exposure may explain the weak correlation between the severity of vascular remodeling and hemodynamic measurements. In addition, despite significant lumen obliteration, the degree of muscularization of pulmonary arteries with a diameter between 20 and $100 \mu \mathrm{m}$, analyzed in this study, may not suffice to induce severe RVSP and RV hypertrophy. For example, in the Sugen5416/hypoxia mouse model of PAH, the increase in RVSP values from 32 to $50 \mathrm{mmHg}$ was induced when $>60 \%$ of pulmonary arterioles were affected by muscularization (27\% partial muscularization and $37 \%$ full muscularization). ${ }^{32}$ In fact, our data are similar to other murine models showing that pulmonary arterial remodeling, even when present at an advanced degree, does not necessarily cause pulmonary hypertension. ${ }^{33}$ These observations support the clinical studies showing that pulmonary vascular remodeling has limited diagnostic value because they are present in all forms of severity of pulmonary hyperten$\operatorname{sion}^{27}$; it may explain, at least to some extent, the discrepancy between significant vascular remodeling associated with only mild elevation of pulmonary arterial pressure, often observed in PAH patients.

Another murine model, generated by lung-specific overexpression of IL-6, replicates the pathological lesions observed in advanced PAH, including both distal arteriolar muscularization and plexogenic arteriopathy, and increased pulmonary vascular resistance and $\mathrm{PAH} .{ }^{34}$ Similar to our model, under normoxic conditions, these mice did not develop pulmonary hypertension. However, on chronic hypoxia exposure, the mice with lung-specific overexpression of IL-6 developed severe pulmonary hypertension and robust RV hypertrophy. Furthermore, this transgenic mouse model developed fully and partially occluded vessels, and the vascular lesions reproduced some molecular features of human plexiform lesions. ${ }^{34}$ Implications of inflammatory cytokines in PAH pathogenesis has also been suggested by the severe PAH phenotype of fat-fed mice with double knockout for apolipoprotein E and IL-1 receptor type 1; interestingly, lung-specific expression of a putative alternate IL-1 receptor 1 receptor transcript was found to be responsible for the severe PAH phenotype of this murine model. ${ }^{35}$

Another interesting case of pulmonary vascular remodeling and plexiform-like arteriopathy without significant pulmonary hypertension, implicating inflammatory cytokines in disease pathogenesis, is the case of murine schistosomias. ${ }^{36}$ Chronic low-dose infection of mice with Schistosoma mansoni led to pulmonary granuloma formation and marked pulmonary vascular remodeling, including the formation of plexiform-like lesions, associated with perivascular inflammation, despite a lack of significant right ventricular hypertrophy. The degree of remodeling correlated with lung egg burden and with circulating cytokine levels. ${ }^{36}$

Recently, the prolyl-4 hydroxylase 2/hypoxia-inducible factor- $2 \alpha$ axis, reported to regulate inflammatory responses, has been implicated in PAH pathogenesis; prolyl-4 hydroxylase 2 is the main oxygen sensor that controls hypoxia-inducible factor activity under normoxia. ${ }^{37,38}$ Deficiency of prolyl-4 hydroxylase 2 in mouse lung ECs and hematopoietic cells triggered severe PAH with extensive pulmonary vascular remodeling, including vascular occlusion and plexiform-like lesions. ${ }^{39}$ A potential role of inflammatory mediators in PAH pathogenesis is presently a promising area of investigation. Remodeled pulmonary arteries exhibit infiltrates of inflammatory cells, elevated levels of growth factors and cytokines (IL-1 and IL-6), and increases in the chemokine regulated on activation, normal 
T-cell expressed and secreted and the macrophage inflammatory protein- $1 \alpha,{ }^{2,34}$ suggesting that inflammation plays an important role in PAH development. Thus, a major finding of our study is that in our murine model, the various degrees of concentric intimal thickening, the muscularization of arteriolar wall, and development of the plexogenic lesions were triggered by a granzyme $\mathrm{B}$ proteolytic cleavage fragment of ITSN, further supporting the idea of inflammation as a promoting mechanism that contributes to pulmonary vascular remodeling in $\mathrm{PAH}$. Whether plexiform lesions are a morphological consequence of inflammation, of high blood pressure as in the SU5416/hypoxia/normoxia rat model, ${ }^{18}$ or of BMPR2 mutations, ${ }^{40}$ it seems that formation of plexiform lesions is a multifactorial process and when they form, they contribute to and sustain the remodeling of the pulmonary vasculature and $\mathrm{PAH}$ progression.

Similar to cultured ECs, myc-EH ITSN $_{\text {expression in }}$ mouse lung leads to activation of $\mathrm{p} 38^{\mathrm{MAPK}}$-dependent proproliferative signaling. Increasing evidence implicates p3 $8^{\mathrm{MAPK}}$ in cell proliferation and vascular obliteration that characterize $\mathrm{PAH}{ }^{41-43}$ All bone morphogenetic protein type II receptor mutations underlying primary $\mathrm{PAH}$ demonstrate a gain of function involving up-regulation of p38 ${ }^{\mathrm{MAPK}}$-dependent proproliferative pathways. ${ }^{43}$ Still, the molecular mechanisms responsible are not well understood. P $38^{\text {MAPK }}$ is generally known as a stress kinase believed to mediate cell death. ${ }^{44,45}$ Several studies and ours indicated, however, that p38 signaling may also be essential for cell survival and proliferation, instead of death. ${ }^{11,46}$ We show now that $\mathrm{p} 38^{\mathrm{MAPK}}$ activation mediates the proliferative potential of $\mathrm{EH}_{\text {ITSN }}$, in vivo, via downstream activation of the Elk-1 transcription factor and increased expression of the immediate early response gene $c$-Fos.

ITSN is a multimodular protein involved in regulation of prosurvival and antiapoptotic events. ${ }^{47,48}$ Recently, we have shown that chronic ITSN deficiency up-regulated extracellular signal regulated kinase (Erk) $1 / 2^{\mathrm{MAPK}}$ activity, suppressed the proapoptotic $\mathrm{Bad}$, and altered Smads signaling downstream of the transforming growth factor- $\beta$ receptor-1, resulting in a proliferative apoptotic-resistant EC phenotype. ${ }^{12}$ In a PAH environment, ITSN deficiency and concurrent expression of granzyme B cleavage products of ITSN, able to regulate the p38 to Erk1/2 activity ratio, appear to be critical for initiation of the aberrant EC proliferation. ${ }^{11}$ The C-terminus granzyme $\mathrm{B}$ cleavage product of ITSN, comprising five consecutive SH3 domains, acts as dominant negative on Ras/Erk1/2 prosurvival signaling. ${ }^{49}$ Moreover, the opposing effects of p38 activation on Erk1/2 ${ }^{50}$ may further contribute to the high p38/ Erk $1 / 2^{\mathrm{MAPK}}$ activity ratio, and subsequently to abnormal EC proliferation. These observations strongly suggest that down-regulation of ITSN and the presence of the $\mathrm{NH}_{2}-$ terminal $\mathrm{EH}_{\text {ITSN }}$ fragment with $\mathrm{EC}$ proliferative potential are key for formation of obliterative and plexiform lesions in severe PAH and that the $\mathrm{EH}_{\mathrm{ITSN}}$, a biologically active protein fragment, present in the lungs of experimental models of PAH and human PAH specimens, may be the trigger for the formation of pulmonary lesions. A potential limitation of our murine model is that pulmonary ECs were transduced only with the $\mathrm{NH}_{2}$-terminal protein fragment produced by granzyme B cleavage of ITSN; the potential contribution of the C-terminal fragment to this mouse phenotype was not considered. However, as previously reported, in late-stage PAH, when pulmonary artery ECs display a stable hyperproliferative phenotype, ITSN and $\mathrm{EH}_{\text {ITSN }}$ expression could be regulated at the mRNA levels by alternative mRNA splicing, a process highly characteristic to ITSN $^{51}$; it is likely that ITSN's cleavage by granzyme B with generation of the $\mathrm{EH}_{\mathrm{ITSN}}$ is just the trigger for excessive EC proliferation and formation of vascular lesions and that the expression of alternatively spliced $\mathrm{EH}_{\text {ITSN }}$ transcript may be responsible for PAH progression and severe arteriopathy.

Given that the motif NPF (Asn-Pro-Phe) is the essential target of EH domains ${ }^{15}$ and our recent studies showing that the proliferative potential of ECs expressing myc-GrB$\mathrm{EH}_{\text {ITSN }}$ (in culture and in vivo) treated with a membrane permeant peptide containing the NPF motif is significantly diminished, ${ }^{52}$ it is attractive to speculate that the $\mathrm{EH}_{\text {ITSN }}$ is a highly specific molecular target that could be used to ameliorate and perhaps reverse the EC plexiform phenotype already established in severe human PAH.

In summary, we have demonstrated that expression of the $\mathrm{EH}_{\text {ITSN }}$ triggers various forms of vascular remodeling, including obliterative and complex plexiform-like lesions, as seen in PAH patients and that $\mathrm{EH}_{\text {ITSN }}$ triggers a novel p38 $8^{\mathrm{MAPK}} /$ Elk-1/c-Fos-dependent molecular mechanism underlying formation of obliterative and complex plexiform-like lesions in the mouse model.

\section{Supplemental Data}

Supplemental material for this article can be found at http://dx.doi.org/10.1016/j.ajpath.2016.11.012.

\section{References}

1. Tuder RM, Cool CD, Yeager M, Taraseviciene-Stewart L, Bull TM, Voelkel NF: The pathobiology of pulmonary hypertension: endothelium. Clin Chest Med 2001, 22:405-418

2. Tuder RM, Marecki JC, Richter A, Fijalkowska I, Flores S: Pathology of pulmonary hypertension. Clin Chest Med 2007, 28:23-42. vii

3. Voelkel NF, Cool C: Pathology of pulmonary hypertension. Cardiol Clin 2004, 22:343-351. v

4. Tuder RM, Abman SH, Braun T, Capron F, Stevens T, Thistlethwaite PA, Haworth SG: Development and pathology of pulmonary hypertension. J Am Coll Cardiol 2009, 54:S3-S9

5. Rabinovitch M: Molecular pathogenesis of pulmonary arterial hypertension. J Clin Invest 2008, 118:2372-2379

6. Tuder RM, Groves B, Badesch DB, Voelkel NF: Exuberant endothelial cell growth and elements of inflammation are present in plexiform lesions of pulmonary hypertension. Am J Pathol 1994, 144: 275-285 
7. Sakao S, Tatsumi K, Voelkel NF: Endothelial cells and pulmonary arterial hypertension: apoptosis, proliferation, interaction and transdifferentiation. Respir Res 2009, 10:95

8. Savai R, Pullamsetti SS, Kolbe J, Bieniek E, Voswinckel R, Fink L, Scheed A, Ritter C, Dahal BK, Vater A, Klussmann S, Ghofrani HA, Weissmann N, Klepetko W, Banat GA, Seeger W, Grimminger F, Schermuly RT: Immune and inflammatory cell involvement in the pathology of idiopathic pulmonary arterial hypertension. Am J Respir Crit Care Med 2012, 186:897-908

9. Buzza MS, Hirst CE, Bird CH, Hosking P, McKendrick J, Bird PI: The granzyme B inhibitor, PI-9, is present in endothelial and mesothelial cells, suggesting that it protects bystander cells during immune responses. Cell Immunol 2001, 210:21-29

10. Austin ED, Rock MT, Mosse CA, Vnencak-Jones CL, Yoder SM, Robbins IM, Loyd JE, Meyrick BO: T lymphocyte subset abnormalities in the blood and lung in pulmonary arterial hypertension. Respir Med 2010, 104:454-462

11. Patel M, Predescu D, Tandon R, Bardita C, Pogoriler J, Bhorade S, Wang M, Comhair S, Hemnes AR, Chen J, Machado R, Husain A, Erzurum S, Predescu S: A novel p38 mitogen-activated protein kinase/Elk-1 transcription factor-dependent molecular mechanism underlying abnormal endothelial cell proliferation in plexogenic pulmonary arterial hypertension. J Biol Chem 2013, 288: 25701-25716

12. Bardita C, Predescu D, Justice MJ, Petrache I, Predescu S: In vivo knockdown of intersectin-1s alters endothelial cell phenotype and causes microvascular remodeling in the mouse lungs. Apoptosis 2013, 18:57-76

13. Yu Y, Chu PY, Bowser DN, Keating DJ, Dubach D, Harper I, Tkalcevic J, Finkelstein DI, Pritchard MA: Mice deficient for the chromosome 21 ortholog Itsn1 exhibit vesicle-trafficking abnormalities. Hum Mol Genet 2008, 17:3281-3290

14. Predescu DN, Neamu R, Bardita C, Wang M, Predescu SA: Impaired caveolae function and upregulation of alternative endocytic pathways induced by experimental modulation of intersectin-1s expression in mouse lung endothelium. Biochem Res Int 2012, 2012:672705

15. de Beer T, Carter RE, Lobel-Rice KE, Sorkin A, Overduin M: Structure and Asn-Pro-Phe binding pocket of the Eps15 homology domain. Science 1998, 281:1357-1360

16. Tschanz SA, Burri PH, Weibel ER: A simple tool for stereological assessment of digital images: the STEPanizer. J Microsc 2011, 243:47-59

17. Stacher E, Graham BB, Hunt JM, Gandjeva A, Groshong SD, McLaughlin VV, Jessup M, Grizzle WE, Aldred MA, Cool CD, Tuder RM: Modern age pathology of pulmonary arterial hypertension. Am J Respir Crit Care Med 2012, 186:261-272

18. Abe K, Toba M, Alzoubi A, Ito M, Fagan KA, Cool CD, Voelkel NF, McMurtry IF, Oka M: Formation of plexiform lesions in experimental severe pulmonary arterial hypertension. Circulation 2010, 121: $2747-2754$

19. McLean JW, Fox EA, Baluk P, Bolton PB, Haskell A, Pearlman R, Thurston G, Umemoto EY, McDonald DM: Organ-specific endothelial cell uptake of cationic liposome-DNA complexes in mice. Am J Physiol 1997, 273:H387-H404

20. Thurston G, McLean JW, Rizen M, Baluk P, Haskell A, Murphy TJ, Hanahan D, McDonald DM: Cationic liposomes target angiogenic endothelial cells in tumors and chronic inflammation in mice. J Clin Invest 1998, 101:1401-1413

21. Miyawaki-Shimizu K, Predescu D, Shimizu J, Broman M, Predescu S, Malik AB: siRNA-induced caveolin-1 knockdown in mice increases lung vascular permeability via the junctional pathway. Am J Physiol Lung Cell Mol Physiol 2006, 290:L405-L413

22. Sakurai F, Inoue R, Nishino $\mathrm{Y}$, Okuda A, Matsumoto O, Taga T, Yamashita F, Takakura Y, Hashida M: Effect of DNA/liposome mixing ratio on the physicochemical characteristics, cellular uptake and intracellular trafficking of plasmid DNA/cationic liposome complexes and subsequent gene expression. J Control Release 2000, 66:255-269
23. Zuhorn IS, Bakowsky U, Polushkin E, Visser WH, Stuart MC, Engberts JB, Hoekstra D: Nonbilayer phase of lipoplex-membrane mixture determines endosomal escape of genetic cargo and transfection efficiency. Mol Ther 2005, 11:801-810

24. Zuhorn IS, Kalicharan R, Hoekstra D: Lipoplex-mediated transfection of mammalian cells occurs through the cholesterol-dependent clathrin-mediated pathway of endocytosis. J Biol Chem 2002, 277 : 18021-18028

25. Zhu L, Mahato RI: Lipid and polymeric carrier-mediated nucleic acid delivery. Expert Opin Drug Deliv 2010, 7:1209-1226

26. Chen J, Tang H, Sysol JR, Moreno-Vinasco L, Shioura KM, Chen T, Gorshkova I, Wang L, Huang LS, Usatyuk PV, Sammani S, Zhou G, Raj JU, Garcia JG, Berdyshev E, Yuan JX, Natarajan V, Machado RF: The sphingosine kinase 1/sphingosine-1-phosphate pathway in pulmonary arterial hypertension. Am J Respir Crit Care Med 2014, 190:1032-1043

27. Pietra GG, Capron F, Stewart S, Leone O, Humbert M, Robbins IM, Reid LM, Tuder RM: Pathologic assessment of vasculopathies in pulmonary hypertension. J Am Coll Cardiol 2004, 43:25S-32S

28. Mooi WJ: Histopathology of Spitz naevi and "Spitzoid" melanomas. Curr Top Pathol 2001, 94:65-77

29. Wagenvoort CA: Plexogenic arteriopathy. Thorax 1994, 49(Suppl): S39-S45

30. Shimoda LA, Laurie SS: Vascular remodeling in pulmonary hypertension. J Mol Med 2013, 91:297-309

31. Gomez-Arroyo J, Saleem SJ, Mizuno S, Syed AA, Bogaard HJ, Abbate A, Taraseviciene-Stewart L, Sung Y, Kraskauskas D, Farkas D, Conrad DH, Nicolls MR, Voelkel NF: A brief overview of mouse models of pulmonary arterial hypertension: problems and prospects. Am J Physiol Lung Cell Mol Physiol 2012, 302:L977-L991

32. Ciuclan L, Bonneau O, Hussey M, Duggan N, Holmes AM, Good R, Stringer R, Jones P, Morrell NW, Jarai G, Walker C, Westwick J, Thomas M: A novel murine model of severe pulmonary arterial hypertension. Am J Respir Crit Care Med 2011, 184:1171-1182

33. Daley E, Emson C, Guignabert C, de Waal Malefyt R, Louten J, Kurup VP, Hogaboam C, Taraseviciene-Stewart L, Voelkel NF, Rabinovitch M, Grunig E, Grunig G: Pulmonary arterial remodeling induced by a Th2 immune response. J Exp Med 2008, 205:361-372

34. Steiner MK, Syrkina OL, Kolliputi N, Mark EJ, Hales CA, Waxman AB: Interleukin-6 overexpression induces pulmonary hypertension. Circ Res 2009, 104:236-244. 28p following 44

35. Lawrie A, Hameed AG, Chamberlain J, Arnold N, Kennerley A, Hopkinson K, Pickworth J, Kiely DG, Crossman DC, Francis SE: Paigen diet-fed apolipoprotein E knockout mice develop severe pulmonary hypertension in an interleukin-1-dependent manner. Am J Pathol 2011, 179:1693-1705

36. Crosby A, Jones FM, Southwood M, Stewart S, Schermuly R, Butrous G, Dunne DW, Morrell NW: Pulmonary vascular remodeling correlates with lung eggs and cytokines in murine schistosomiasis. Am J Respir Crit Care Med 2010, 181:279-288

37. Takeda K, Ichiki $\mathrm{T}$, Narabayashi E, Inanaga $\mathrm{K}$, Miyazaki R, Hashimoto T, Matsuura H, Ikeda J, Miyata T, Sunagawa K: Inhibition of prolyl hydroxylase domain-containing protein suppressed lipopolysaccharide-induced TNF-alpha expression. Arterioscler Thromb Vasc Biol 2009, 29:2132-2137

38. Kapitsinou PP, Rajendran G, Astleford L, Michael M, Schonfeld MP, Fields T, Shay S, French JL, West J, Haase VH: The endothelial prolyl-4-hydroxylase domain 2/hypoxia-inducible factor 2 axis regulates pulmonary artery pressure in mice. Mol Cell Biol 2016, 36: $1584-1594$

39. Dai Z, Li M, Wharton J, Zhu MM, Zhao YY: Prolyl-4 hydroxylase 2 (PHD2) deficiency in endothelial cells and hematopoietic cells induces obliterative vascular remodeling and severe pulmonary arterial hypertension in mice and humans through hypoxia-inducible factor2alpha. Circulation 2016, 133:2447-2458

40. Toshner M, Voswinckel R, Southwood M, Al-Lamki R, Howard LS, Marchesan D, Yang J, Suntharalingam J, Soon E, 
Exley A, Stewart S, Hecker M, Zhu Z, Gehling U, Seeger W, PepkeZaba J, Morrell NW: Evidence of dysfunction of endothelial progenitors in pulmonary arterial hypertension. Am J Respir Crit Care Med 2009, 180:780-787

41. Yang X, Long L, Southwood M, Rudarakanchana N, Upton PD, Jeffery TK, Atkinson C, Chen H, Trembath RC, Morrell NW: Dysfunctional Smad signaling contributes to abnormal smooth muscle cell proliferation in familial pulmonary arterial hypertension. Circ Res 2005, 96:1053-1063

42. Mortimer HJ, Peacock AJ, Kirk A, Welsh DJ: p38 MAP kinase: essential role in hypoxia-mediated human pulmonary artery fibroblast proliferation. Pulm Pharmacol Ther 2007, 20:718-725

43. Rudarakanchana N, Flanagan JA, Chen H, Upton PD, Machado R, Patel D, Trembath RC, Morrell NW: Functional analysis of bone morphogenetic protein type II receptor mutations underlying primary pulmonary hypertension. Hum Mol Genet 2002, 11: $1517-1525$

44. Han JY, Jeong JY, Lee YK, Roh GS, Kim HJ, Kang SS, Cho GJ, Choi WS: Suppression of survival kinases and activation of JNK mediate ethanol-induced cell death in the developing rat brain. Neurosci Lett 2006, 398:113-117

45. Hui L, Bakiri L, Stepniak E, Wagner EF: p38alpha: a suppressor of cell proliferation and tumorigenesis. Cell Cycle 2007, 6: $2429-2433$
46. Thornton TM, Rincon M: Non-classical p38 map kinase functions: cell cycle checkpoints and survival. Int J Biol Sci 2009, 5:44-51

47. Predescu SA, Predescu DN, Knezevic I, Klein IK, Malik AB: Intersectin-1s regulates the mitochondrial apoptotic pathway in endothelial cells. J Biol Chem 2007, 282:17166-17178

48. Das M, Scappini E, Martin NP, Wong KA, Dunn S, Chen YJ, Miller SL, Domin J, O'Bryan JP: Regulation of neuron survival through an intersectin-phosphoinositide 3'-kinase C2beta-AKT pathway. Mol Cell Biol 2007, 27:7906-7917

49. Tong XK, Hussain NK, Adams AG, O'Bryan JP, McPherson PS: Intersectin can regulate the Ras/MAP kinase pathway independent of its role in endocytosis. J Biol Chem 2000, 275:29894-29899

50. Fey D, Croucher DR, Kolch W, Kholodenko BN: Crosstalk and signaling switches in mitogen-activated protein kinase cascades. Front Physiol 2012, 3:355

51. Kropyvko S, Gerasymchuk D, Skrypkina I, Dergai M, Dergai O, Nikolaienko O, Rynditch A, Tsyba L: Structural diversity and differential expression of novel human intersectin 1 isoforms. Mol Biol Rep 2010, 37:2789-2796

52. Predescu S, Patel M, Chen JDP: Targeted delivery of the NH2-terminal fragment of intersectin-1s triggers formation of complex plexiform lesions in mouse lungs. American Thoracic Society 2015 International Conference [abstract A51]. May 15-20, 2015, Denver, CO. American Thoracic Society, 2015 